\title{
On the theory of the $\mathrm{CO}+\mathrm{OH}$ reaction, including $\mathrm{H}$ and $\mathrm{C}$ kinetic isotope effects
}

\author{
Wei-Chen Chen and R. A. Marcus ${ }^{a)}$ \\ Noyes Laboratory, 127-72 California Institute of Technology, Pasadena, California 91125
}

(Received 1 February 2005; accepted 15 July 2005; published online 8 September 2005)

\begin{abstract}
The effect of pressure, temperature, H/D isotopes, and $\mathrm{C}$ isotopes on the kinetics of the $\mathrm{OH}$ $+\mathrm{CO}$ reaction are investigated using Rice-Ramsperger-Kassel-Marcus theory. Pressure effects are treated with a step-ladder plus steady-state model and tunneling effects are included. New features include a treatment of the $\mathrm{C}$ isotope effect and a proposed nonstatistical effect in the reaction. The latter was prompted by existing kinetic results and molecular-beam data of Simons and co-workers [J. Phys. Chem. A 102, 9559 (1998); J. Chem. Phys. 112, 4557 (2000); 113, 3173 (2000)] on incomplete intramolecular energy transfer to the highest vibrational frequency mode in $\mathrm{HOCO}^{*}$. In treating the many kinetic properties two small customary vertical adjustments of the barriers of the two transition states were made. The resulting calculations show reasonable agreement with the experimental data on (1) the pressure and temperature dependence of the H/D effect, (2) the pressure-dependent ${ }^{12} \mathrm{C} /{ }^{13} \mathrm{C}$ isotope effect, (3) the strong non-Arrhenius behavior observed at low temperatures, (4) the high-temperature data, and (5) the pressure dependence of rate constants in various bath gases. The kinetic carbon isotopic effect is usually less than 10 per mil. A striking consequence of the nonstatistical assumption is the removal of a major discrepancy in a plot of the $k_{\mathrm{OH}+\mathrm{CO}} / k_{\mathrm{OD}+\mathrm{CO}}$ ratio versus pressure. A prediction is made for the temperature dependence of the $\mathrm{OD}+\mathrm{CO}$ reaction in the low-pressure limit at low temperatures. (C) 2005 American Institute of Physics. [DOI: 10.1063/1.2031208]
\end{abstract}

\section{INTRODUCTION}

The reaction of $\mathrm{CO}$ with the $\mathrm{OH}$ radical plays a major role in both atmospheric and combustion chemistry. ${ }^{1,2}$ The reaction is known to be the principal oxidation which converts $\mathrm{CO}$ to $\mathrm{CO}_{2}$ in the atmosphere, ${ }^{1}$ and is also the key reaction controlling the $\mathrm{OH}$ radical concentration in the lower atmosphere. ${ }^{1}$ Reflecting its importance and the unusual temperature and pressure dependence of its rate constant, the $\mathrm{CO}+\mathrm{OH} \rightarrow \mathrm{CO}_{2}+\mathrm{H}$ reaction has been examined extensively in many experimental ${ }^{3-17}$ and theoretical studies, ${ }^{17-28}$ including experimental studies over a very wide range of temperatures and pressures. ${ }^{4-13,17}$ Nevertheless, carbon and oxygen isotope effects have been observed ${ }^{29-33}$ and the anomalous effects for these heavy-atom isotopes have not yet been treated in the literature. Again, Simons and co-workers ${ }^{63-65}$ observed in their molecular-beam study of the reverse reaction, $\mathrm{H}+\mathrm{CO}_{2} \rightarrow \mathrm{OH}+\mathrm{CO}$, that the vibrational excitation of the $\mathrm{CO}$ product was far below that expected from statistical theory for the $\mathrm{HOCO}^{*}$ intermediate. While the energies in their experiments are higher than those normally occurring in the $\mathrm{OH}+\mathrm{CO}$ reaction, it is interesting to look for other anomalies in that reaction which may be better explained by a nonstatistical modification of the Rice-Ramsperger-KasselMarcus (RRKM) theory. Furthermore, there is a discrepancy in the H/D isotope effect in the literature. ${ }^{27}$ The present work treats these various observations.

The radical intermediate HOCO has been observed both

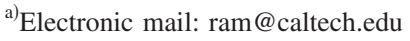

in the gas phase and in a matrix. ${ }^{16,34-36}$ The ionization potential, energy of formation, and vibrational and rotational spectroscopy of the radical have also been characterized. 3,35 Studies of the kinetics of HOCO formation have firmly established the connection between the reactants $(\mathrm{OH}+\mathrm{CO})$ and the products $\left(\mathrm{H}+\mathrm{CO}_{2}\right){ }^{16}$ The currently accepted reaction mechanism includes an $\mathrm{OH}$ and $\mathrm{CO}$ bimolecular association step producing a vibrationally excited trans-HOCO, followed by cis-trans isomerization. The final reaction steps in competition with each other are dissociation to $\mathrm{H}$ and $\mathrm{CO}_{2}$, back reaction to $\mathrm{OH}$ and $\mathrm{CO}$, and collisional stabilization. ${ }^{5,13,16,17,21,22}$ As the pressure increases, the collisional stabilization of the cis- and trans-HOCO intermediates competes favorably with the dissociation channel and the back reaction. When $\mathrm{OH}$ and $\mathrm{CO}$ react in oxygen, both the dissociation channel and the collision stabilization lead to $\mathrm{HO}_{2}$ and $\mathrm{CO}_{2}$, because of the follow-up reactions of $\mathrm{H}$ and HOCO with $\mathrm{O}_{2} \cdot{ }^{37-39}$ The present paper treats the dependence of the rate constants on temperature, pressure, foreign gases, and $\mathrm{H} / \mathrm{D}$ and ${ }^{12} \mathrm{C} /{ }^{13} \mathrm{C}$ isotope effects. Interpretation of the oxygen isotope effects ${ }^{31-33}$ is complex and is discussed in a second paper.

The experimental study of the $\mathrm{OH}+\mathrm{CO}$ reaction covers a temperature range from 80 to $3150 \mathrm{~K} .^{4-13,17}$ A marked change of activation energy occurs near $500 \mathrm{~K}$. The pressure and bath gas dependence of the reaction rate have also been measured, ${ }^{11-15,17,40}$ as has the pressure and temperature dependence of the $\mathrm{OD}+\mathrm{CO}$ reaction. ${ }^{11,17,41}$ The $k_{\mathrm{OH}+\mathrm{CO}} / k_{\mathrm{OD}+\mathrm{CO}}$ ratio shows a pressure-dependent H/D isotope effect. Further 
TABLE I. Calculated geometries and vibrational frequencies of normal isotopes by CC. The units are in $\AA$ for bond length, in degree for angles and dihedral angles, and in $\mathrm{cm}^{-1}$ for vibrational frequencies.

\begin{tabular}{|c|c|c|c|c|c|c|}
\hline & $\mathrm{OH}+\mathrm{CO}^{\prime}$ & $\mathrm{TS}_{a}$ & cis-HOCO' & trans-HOCO' & $\mathrm{TS}_{d}$ & $\mathrm{CO}_{2}$ \\
\hline $\mathrm{R}_{\mathrm{OH}}$ & 0.976 & 0.975 & 0.976 & 0.967 & 1.345 & \\
\hline $\mathrm{R}_{\mathrm{CO}}$ & 1.148 & 2.033 & 1.342 & 1.358 & 1.227 & 1.177 \\
\hline $\mathrm{R}_{\mathrm{CO}^{\prime}}$ & & 1.150 & 1.199 & 1.194 & 1.184 & 1.177 \\
\hline$\theta_{\mathrm{HOC}}$ & & 94.86 & 107.74 & 107.37 & 116.27 & \\
\hline$\theta_{\mathrm{OCO}^{\prime}}$ & & 123.52 & 129.61 & 126.38 & 155.28 & 180.00 \\
\hline $\mathrm{d}_{\mathrm{HOCO}^{\prime}}$ & & 180.00 & 0.00 & 180.00 & 0.00 & \\
\hline$\nu_{1}$ & $2154^{a}$ & $312 i$ & 596 & 533 & $2125 i$ & 639 \\
\hline$\nu_{2}$ & $3763^{b}$ & 197 & 594 & 606 & 518 & 639 \\
\hline$\nu_{3}$ & & 244 & 1091 & 1090 & 640 & 1345 \\
\hline$\nu_{4}$ & & 752 & 1321 & 1262 & 945 & 2410 \\
\hline$\nu_{5}$ & & 2122 & 1868 & 1903 & 1298 & \\
\hline$\nu_{6}$ & & 3784 & 3707 & 3869 & 2157 & \\
\hline
\end{tabular}

experimental kinetic isotopic studies with ${ }^{18} \mathrm{OH},{ }^{13} \mathrm{CO}$, $\mathrm{C}^{17} \mathrm{O}$, and $\mathrm{C}^{18} \mathrm{O}$ have also been performed. These results provide a body of data for tests of $a b$ initio or other potential-energy surfaces and of reaction-rate theory. In particular, there is a serious discrepancy between the observed and calculated plot of $\mathrm{OH} / \mathrm{OD}$ rates versus pressure.

Stevens et al. appear to be the first group to study experimentally the kinetic isotope effects for carbon and oxygen in the reaction. ${ }^{29}$ They measured the isotopic ratios of the unreacted $\mathrm{CO}$ and of the $\mathrm{CO}_{2}$ formed in the reaction mass spectrometrically and obtained pressure-dependent fractionation of ${ }^{13} \mathrm{C} /{ }^{12} \mathrm{C}$ and ${ }^{18} \mathrm{O} /{ }^{16} \mathrm{O}$ at pressures from 150 to 800 torr. In a similar but independent study Smit et al. ${ }^{30}$ obtained results for the fractionation between carbon isotopes, which were consistent with those of Stevens et al. Their investigations were prompted by the need for understanding the global budget of atmospheric ${ }^{12} \mathrm{CO}$ and ${ }^{13} \mathrm{CO}$. The enrichment of oxygen isotopes in $\mathrm{CO}$ was found to be nonconventional in its mass dependence, i.e., it did not obey the usual "mass-dependent" theoretically based and usually applicable rule of Bigeleisen and Mayer. ${ }^{42}$

Results similar to those of Stevens et al. ${ }^{29}$ were obtained by Röckmann et al. ${ }^{31}$ Laboratory studies of isotope effects were also made by Feilberg et al., ${ }^{32,33}$ whose results do not agree with those of Röckmann et al. and Stevens et al. The experimental precursors generating the $\mathrm{OH}$ radicals are different. The experimental conditions of Röckmann et al. are simpler in that ozone was not added and so there were fewer chemical reactions in the overall scheme. While $\mathrm{HO}_{2}$ may be a dominant product in the studies of Stevens et al. and Röckmann et al., due to the reaction of the source material $\mathrm{H}_{2} \mathrm{O}_{2}$ with $\mathrm{OH}$, the rate constant for the reaction of $\mathrm{CO}$ with $\mathrm{HO}_{2}$ is extremely small, less than $10^{-27} \mathrm{~cm}^{3}$ molecule $\mathrm{s}^{-1}$ at room temperature, ${ }^{43}$ and so is about 14 orders of magnitude smaller than that of $\mathrm{CO}$ with $\mathrm{OH}$. The $\mathrm{HO}_{2}$ is therefore not expected to interfere in the analysis.

Dynamical and statistical treatments of the $\mathrm{CO}+\mathrm{OH}$ reactions have been made with various theoretical methods, ${ }^{17,20-25}$ including quasiclassical trajectories, quantum dynamics, transition state theory, and RRKM theory. In the present article we focus on the statistical and nonstatisti- cal aspects of the reaction over a wide temperature region for the different experimental conditions, as well as the hydrogen and carbon isotope effects.

The carbon isotope effect is typically less than 10 per mil at these pressures and temperatures. In the present study, RRKM theory and a nonstatistical modification are used, together with nuclear tunneling corrections and a step-ladder model for collision stabilization. Like the previous study by Senosiain et al. ${ }^{27}$ the resulting theory reproduces a large body of experimental data, apart from the potentially complex O-isotope effect discussed elsewhere. In addition, we treat the $\mathrm{C}$-isotope effect and the large $\mathrm{OH} / \mathrm{OD}$ rate constant discrepancy described in Ref. 27.

The paper is organized as follows: The potential-energy surface used is summarized in Sec. II A. The kinetic scheme for RRKM calculations, approximate tunneling probabilities, step-ladder model for pressure effects, and a possible nonstatistical distribution model for energy transfer at the exit channel are treated in Secs. II B-II E, respectively. Results are given in Sec. III and discussed in Sec. IV.

\section{CALCULATION METHODS}

\section{A. Potential-energy surface}

An $a b$ initio potential-energy surface (PES) was calculated by Zhu et al., ${ }^{21}$ who used the modified GAUSSIAN-2 method (G2M). To obtain the more accurate vibrational frequencies and rotational constants of all stable and TS structures for various isotopes we use a coupled-cluster method, ${ }^{44,45}$ abbreviated as CC. The calculated geometries and vibrational frequencies of normal isotopes are listed in Table I. To test the robustness of certain calculations, particularly of the H/D isotope effects, the results are compared in Appendix A with another modified $a b$ initio potential [Lakin-Troya-Schatz-Harding (LTSH) by Lakin et al.],,$^{24,46}$ and with two other $a b$ initio methods, the MP2 method and a density-functional method (B3LYP), for the vibrational and rotational constants. The GAUSSIAN 98 program $^{47}$ was employed for all $a b$ initio calculations to obtain the principal stable and TS equilibrium structures and their rotational and vibrational constants. 


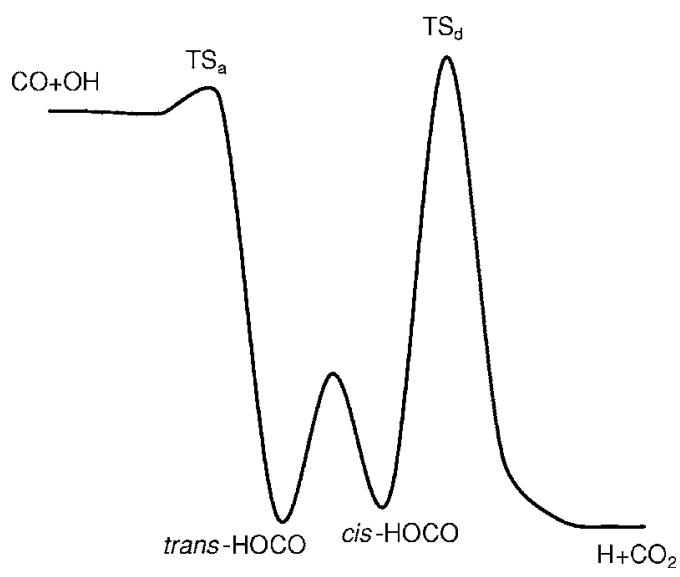

FIG. 1. Schematic profile of potential-energy surface of the $\mathrm{CO}+\mathrm{OH}$ reaction.

A major candidate for the origin of the strong nonArrhenius effect in the rate constant is the tunneling at the transition state $\mathrm{TS}_{d}$ in Fig. 1 for forming $\mathrm{H}+\mathrm{CO}_{2}$ from cisHOCO. This interpretation is consistent with there being a large imaginary frequency at $\mathrm{TS}_{d}, 2126 i \mathrm{~cm}^{-1}$ calculated by CC. The RRKM rate constant in the low-pressure limit at room temperature calculated with this PES was larger than the experimental value by a factor of about 2 . Accordingly, to match the experimental and calculated rate constants, the potential energy of $\mathrm{TS}_{a}$ and $\mathrm{TS}_{d}$ were shifted vertically slightly by two independent constants, $E_{1}$ at $\mathrm{TS}_{a}$ and $E_{2}$ at $\mathrm{TS}_{d}$. (Vertical shifts are commonly used in conjunction with $a b$ initio surfaces.) $E_{1}$ and $E_{2}$ were determined from the rate constants for the $\mathrm{CO}+\mathrm{OH}$ reaction at 100 and $300 \mathrm{~K}$ in the lowpressure limit (Sec. III A). At lower temperatures the barrier at $\mathrm{TS}_{a}$ dominates the rate constant due to the large tunneling at $\mathrm{TS}_{d}$. At room temperature the barriers in both exit and entrance channels of $\mathrm{HOCO}^{*}$ influence the rate constant. With these two constants, $E_{1}$ and $E_{2}$, and an energy-transfer parameter $\alpha$ per collision (Sec. II D), all the remaining properties of the reaction were calculated and compared with the experimental data. When different methods of varying accuracy were used and the shifts $E_{1}$ and $E_{2}$ were made to fit two pieces of data above, the resulting calculated rate constants are similar in all methods, as shown in Appendix A.

\section{B. Kinetic scheme and rate constants}

Microcanonical RRKM theory is used with tunneling corrections $^{48}$ for each quantum state of the two transition state structures. The steady-state equation for pressure effects is then solved. The coordinate assumed for the transition structures is the reaction path with minimal energy. The vibration frequencies of the transition state (TS) structures are fixed in the vicinity of the TS when counting the number of states along the reaction path with variation of the $\mathrm{HO} \ldots \mathrm{CO}$ center-to-center distance, and hence, of the two largest moments of inertia. (A more elaborate variational calculation of selected points will be given elsewhere.) There are van der Waals complexes of $\mathrm{CO}$ and $\mathrm{OH}$ and the loose transition structures to form the $\mathrm{TS}_{a}$, but calculations show that they have only a minor effect on the reaction rates. ${ }^{49}$ Thus, $\operatorname{TS}_{a}$ is the only transition state structure for the entrance channel included in the kinetic scheme. The potential-energy barrier between trans- and cis-HOCO is much lower than the potential energies of the entrance and exit channels, and so the two isomers interconvert in the energetic $\mathrm{HOCO}^{*}$ intermediate. The density of states of $\mathrm{HOCO}^{*}$ is therefore evaluated by summing $\rho_{\text {cis-HOCO }}(E J)$ and $\rho_{\text {trans-HOCO }}(E J)$, which includes the hindered rotation as one of the coordinates in the calculation. In the kinetic scheme, we can simply write HOCO* for the sum of cis-HOCO* and trans-HOCO* . At zero pressure, the following scheme for the reaction of $\mathrm{CO}+\mathrm{OH}$ is used for reaction at any energy $E$ and total angular momentum $J$ :

$$
\begin{gathered}
\mathrm{CO}+\mathrm{OH} \underset{k_{-1}(E J)}{\stackrel{k_{1}(E J)}{\rightleftharpoons}} \mathrm{HOCO}^{*}(E J), \\
\mathrm{HOCO}^{*}(E J) \stackrel{k_{2}(E J)}{\rightarrow} \mathrm{H}+\mathrm{CO}_{2} .
\end{gathered}
$$

At finite pressures an additional series of kinetic equations are added to the scheme:

$$
\mathrm{HOCO}^{*}(E J)+M \stackrel{\omega\left(E J \rightarrow E^{\prime} J^{\prime}\right)}{\rightarrow} \operatorname{HOCO}\left(E^{\prime} J^{\prime}\right)+M,
$$

where $M$ is a third body and $E$ and $J$ are conserved in reaction steps (1) and (2). The rate constants $k_{i}(E J)$ are all $E$ and $J$ dependent. The $\omega\left(E J \rightarrow E^{\prime} J^{\prime}\right)$ is the rate constant per unit $E$ for forming $\mathrm{HOCO}$ at $\left(E^{\prime} J^{\prime}\right)$ from $\mathrm{HOCO}(E J)$ by collision with a third body $M$.

The rate equation for the distribution function, $g(E J)$, for $\mathrm{HOCO}^{*}$ at any specified $(E J)$ per unit energy is

$$
\begin{aligned}
\frac{d g(E J)}{d t}= & k_{1}(E J)-\left[k_{-1}(E J)+k_{2}(E J)+\omega\right] g(E J) \\
& +\sum_{J^{\prime}} \int_{E^{\prime}} \omega\left(E^{\prime} J^{\prime} \rightarrow E J\right) g\left(E^{\prime} J^{\prime}\right) \mathrm{d} E^{\prime},
\end{aligned}
$$

where $g(E J)$ denotes $[\mathrm{HOCO}(E J)] /[\mathrm{CO}][\mathrm{OH}]$. The latter has units of (energy concentration $)^{-1}$. The total collision frequency $\omega$ is

$$
\omega=\sum_{J^{\prime}} \int_{E^{\prime}} \omega\left(E J \rightarrow E^{\prime} J^{\prime}\right) \mathrm{d} E^{\prime} .
$$

This $\omega\left(E J \rightarrow E^{\prime} J^{\prime}\right)$ is described by a step-ladder model employed in Sec. II D.

In the dissociation of the intermediate via $\mathrm{TS}_{d}$, the RRKM rate constant $k_{2}(E J)$ appearing in Eqs. (2) and (4) is

$$
k_{2}(E J)=\frac{N_{d}(E J)}{h \rho(E J)},
$$

where $\rho(E J)$ is the density of states of the corresponding dissociating energetic molecules and $N_{d}(E J)$ is the sum of states of $\mathrm{TS}_{d}$, with the tunneling correction ${ }^{50,51}$ for a microcanonical ensemble of 


$$
N_{d}(E J)=\int_{-\infty}^{E} \kappa_{d}\left(E^{\prime}\right) \rho_{d}\left(\left(E-E^{\prime}\right) J\right) \mathrm{d} E^{\prime}
$$

Here, $\kappa_{d}\left(E^{\prime}\right)$ is the tunneling transmission probability of $\mathrm{TS}_{d}$ when the energy in the H-tunneling coordinate is $E^{\prime}$, and $\rho_{d}\left(\left(E-E^{\prime}\right) J\right)$ denotes the density of states of $\mathrm{TS}_{d}$ at an energy $E-E^{\prime}$ and at total angular momentum $J$.

Harmonic vibrational frequencies and rotational constants for counting $N(E J)$ or $\rho(E J)$ were obtained by electronic structure calculations described in Sec. II A. To account approximately for the anharmonicity of the energetic intermediates, the density of states of trans- and cis-HOCO were increased by a constant factor, 1.5. ${ }^{52}$ For TS, a "loose" TS was assumed. Anharmonicity effects for the vibrations of $\mathrm{OH}$ and $\mathrm{CO}$ are minor. In the calculation of quantum states of the internal rotation about the $\mathrm{HO}-\mathrm{CO}$ bond in $\mathrm{TS}_{a}{ }^{53} \mathrm{cis}$ and trans-HOCO were treated as one-dimensional hindered rotors.

\section{Tunneling calculations with statistical and nonstatistical models}

All $a b$ initio calculations show a sharp potential-energy barrier in the product channel. ${ }^{18,21}$ However, the magnitude of the imaginary frequency of $\mathrm{TS}_{d}$ depends on the electronic structure method used. Although these values are substantially different from each other (they are tabulated later), all of them indicate that the tunneling must be included in calculating the low-temperature reaction rates. ${ }^{54}$ In these systems, in mass-weighted coordinate space the tunneling through the potential barrier occurs entirely in the products' channel and so there is no "corner cutting." proximation to reduce computational time, the tunneling probability $\kappa(E)$ was estimated for passage through an Eckart potential. ${ }^{56}$ The potential was fitted to the paths of steepest ascent and descent through the saddle point. The Eckartfitted approximation was checked with a sampling of more accurate calculations for selected points. In general, the Eckart barrier provides a more accurate but still simple representation than an inverted parabolic potential. However, the tunneling probability in the significant tunneling regions calculated by the Wigner approximation with an inverted parabolic potential is very similar to that calculated using the Eckart approximation. The difference of tunneling probabilities is less than $10 \%$. However, compensation by barrierheight adjustment almost completely removes this discrepancy. Therefore, the bottom shape of the barrier in the exit channel only has a minor effect in the tunneling effect. With a slightly different vertical shift $E$ of $\mathrm{TS}_{d}$, such difference have only a minor effect over the final results.

\section{Pressure effects with statistical and nonstatistical models}

At high temperatures the effect of pressure on all properties in the present region of focus, below 1000 torr, is minor both experimentally and theoretically. However, at low temperatures in this pressure region both the pressure and the nature of the foreign gas affect the reaction rate. The collision frequency for the transition from $E J$ to $E^{\prime} J^{\prime}$,
$\omega\left(E J \rightarrow E^{\prime} J^{\prime}\right)$, is approximated as the product of the total collision frequency $\omega$, the energy transfer probability $P_{E \rightarrow E^{\prime}}$, and the rotational angular momentum transfer probability $P_{J \rightarrow J^{\prime}}: \omega\left(E J \rightarrow E^{\prime} J^{\prime}\right)=\omega P_{E \rightarrow E^{\prime}} P_{J \rightarrow J^{\prime}}$. For angular momentum transfer a strong collision is assumed. Thereby, the transfer probability $P_{J \rightarrow J^{\prime}}$ from $J$ to state $J^{\prime}$ equals the thermal distribution of $J^{\prime}$ states of the intermediate, HOCO, at the given temperature.

In the step-ladder model used for the energy-transfer probability $P_{E \rightarrow E^{\prime}},{ }^{57}$ a certain amount of energy $\alpha$ is transferred in each collision, in the present case between $\mathrm{HOCO}^{*}$ and a bath molecule. The energy-transfer parameter $\alpha$ ( $\alpha$ is positive) is dependent on the bath gas, but is independent of pressure. The $\alpha$ value of each bath gas, determined by best agreement with experimental results ${ }^{11,13,14,17,40}$ of the CO $+\mathrm{OH}$ reaction at pressures below 800 torr, are given later in Table III.

By microscopic reversibility the ratio of activating collisions divided by the deactivating collisions in a step is equal to $[\rho(E) / \rho(E-\Delta E)] e^{-\alpha / k_{B} T}$, where $\rho(E)$ is the density of states of the intermediate at a total energy $E$. When $\rho(E)$ is approximated by a constant for a range of energies near the dissociation threshold, ${ }^{58}$ the probabilities can then be written as

$$
P_{E \rightarrow E^{\prime}}= \begin{cases}\frac{e^{-\alpha / k_{B} T}}{1+e^{-\alpha / k_{B} T}}, & E^{\prime}=E+\alpha \\ \frac{1}{1+e^{-\alpha / k_{B} T}}, & E^{\prime}=E-\alpha \\ 0, & \text { otherwise }\end{cases}
$$

The Lennard-Jones potential was used for interaction between a bath molecule and HOCO. The $\epsilon$ and $\sigma$ parameters for the various bath gases in the Lennard-Jones potential are the same as those calculated by Zhu et al. ${ }^{21}$ The lower limit for the energy range in the present calculations is $3000 \mathrm{~cm}^{-1}$ below the dissociation limit of $\mathrm{CO}$ and $\mathrm{OH}$ formation at the given temperature and pressure; even energies below $-2500 \mathrm{~cm}^{-1}$ are sufficiently lower than the dissociation threshold that the probability of the intermediate reacquiring enough energy to dissociate is negligible. To ensure convergence in the high-temperature and high-pressure region, the upper limit of the energy used in the calculations was $12000 \mathrm{~cm}^{-1}$ above the dissociation limit, and the total angular momentum $J$ covered the range from 0 to 220 in the $E$, $J$-resolved calculation. The energy grain size used for the energy integration in computing the pressure effect on the reaction rate constant was $1 \mathrm{~cm}^{-1} .{ }^{59}$ (For calculations restricted to $500 \mathrm{~K}$ or less, an upper limit of $5000 \mathrm{~cm}^{-1}$ in $E$ and of 100 in $J$ would have sufficed.)

\section{E. OH energy partitioning and nonstatistical modification}

In the RRKM theory it is assumed that the rate of energy redistribution in the intramolecular states of the intermediate is much faster than that of the dissociation. The molecularbeam results of Simons and co-workers for the reaction $\mathrm{H}$ $+\mathrm{CO}_{2} \rightarrow \mathrm{HOCO}^{*} \rightarrow \mathrm{OH}+\mathrm{CO}$ show, albeit at higher energies than the present, that the $\mathrm{CO}$ formed has less energy than would be expected from statistical microcanonical behavior, 


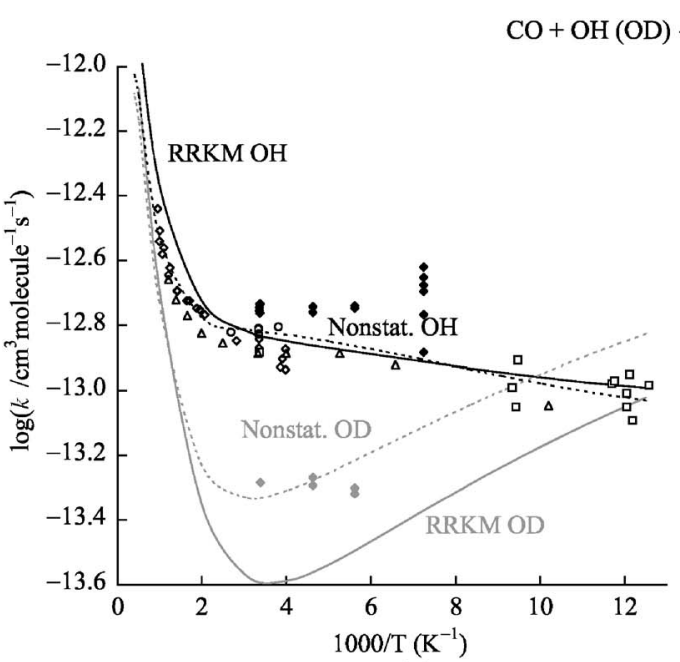

(a)

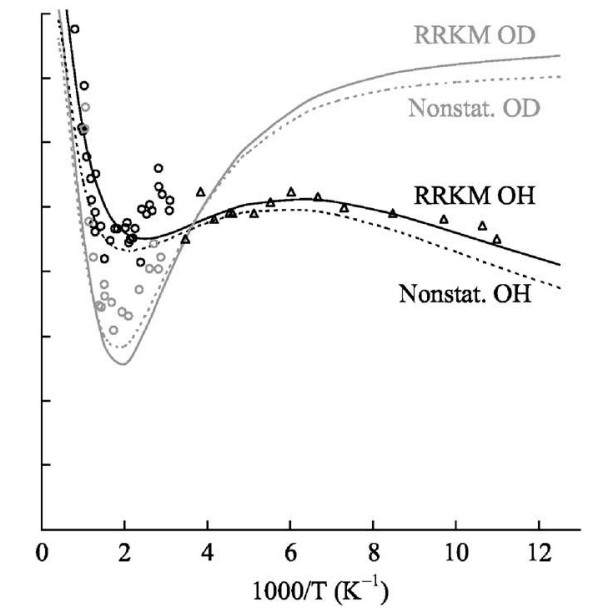

(b)

FIG. 2. Arrhenius plots for $\mathrm{CO}+\mathrm{OH}$ (blacks) and $\mathrm{CO}+\mathrm{OD}$ (grays). The solid and dashed lines are calculated using the RRKM and nonstatistical model, respectively. (a) The open squares and solid diamonds are experimental results obtained for 2-10 torr by Frost et al. (Refs. 11,12). The open diamonds and circles are obtained at 100 and 50-92 torr, respectively, by Ravishankara and co-workers (Refs. 6 and 13). The open triangles are the extrapolated rate constants $\mathrm{CO}+\mathrm{OH}$ at zero pressure obtained by Fulle et al. (Ref. 5). The lines are the calculations at the low-pressure limit. (b) The open circles are the experimental data of Jonah et al. (Ref. 4) for a bath gas of 760 torr of Ar and 15 torr of $\mathrm{H}_{2} \mathrm{O}$. The open triangles are for 760 torr of He obtained by Fulle et al. (Ref. 5). The lines are the present calculations at 785 torr of Ar.

i.e., that there was a limited energy exchange between the newly formed $\mathrm{OH}$ bond and the other coordinates in $\mathrm{H} \cdots \mathrm{OCO}^{*}$. The reaction of $\mathrm{CO}+\mathrm{OH} \rightarrow \mathrm{H}+\mathrm{CO}_{2}$ requires a concentration of energy in the $\mathrm{OH}$ bond stretch in the cis intermediate (Fig. 1). Since the exit channel for the $\mathrm{CO}_{2}$ $+\mathrm{H} \rightarrow \mathrm{CO}+\mathrm{OH}$ reaction is flat (no sharp repulsive drop), there is no major dynamical effect in this exit channel and so the energy distribution of the $\mathrm{CO}$ and $\mathrm{OH}$ products should reflect that expected from statistical theory, ${ }^{60-62}$ applied now to $\mathrm{HOCO}$, with relatively minor corrections for dynamics.

Although the formation of $\mathrm{HOCO}^{*}$ from $\mathrm{OH}+\mathrm{CO}$ is a highly exothermic reaction, the $\mathrm{OH}$ group would still be present largely in its vibrational ground state in a microcanonical distribution $\rho(E J)$ at room temperature, because of the high $\mathrm{OH}$-stretching vibrational frequency. However, since the potential-energy barriers in the entrance and exit channels are similar, a large amount of internal energy in an energetic HOCO molecule needs to be transferred into the $\mathrm{OH}$ bond in order for the $\mathrm{HOCO}$ to dissociate into $\mathrm{CO}_{2}+\mathrm{H}$. After this barrier at exit channel is overcome, the $\mathrm{H}$ atom then dissociates from the OCO. The harmonic energy steps of $\mathrm{OH}$ stretching in $\mathrm{HOCO}$ are about $3600 \mathrm{~cm}^{-1}$, which is larger by $1700 \mathrm{~cm}^{-1}$ than that for the other vibrational modes. Because of this large frequency difference between $\mathrm{OH}$ stretching and the other modes, the internal energy transfer to $\mathrm{OH}$-stretching motion via internal resonances with the other modes may be less rapid than needed for internal equilibration. (A higher-order resonance is possible.) Prompted by the experimental results of Brouard et al. ${ }^{63-65}$ and other results, we have explored, with details in Appendix $\mathrm{C}$, the effect of a reduced intramolecular energy transfer between the $\mathrm{OH}$-stretching-mode motion and the other coordinates.

In this first trial calculation, an intramolecular energytransfer parameter $\xi$ in HOCO is defined in Eq. (C2) for the transfer to and from an $\mathrm{OH}$ vibration and is assumed to be
$4000 \mathrm{~cm}^{-1}$. It is somewhat larger than the vibrational frequency of the $\mathrm{OH}$ stretching in the $\mathrm{HOCO}^{*}$, so allowing the intramolecular transfer of roughly one $\mathrm{OH}$ vibrational quantum. The nonstatistical modification significantly improves the agreement with the data for the rate constants of $\mathrm{CO}$ $+\mathrm{OH}$ at high temperatures, the rate constants of $\mathrm{CO}+\mathrm{OD}$ at low pressures at room temperature, and the $k_{\mathrm{OH}+\mathrm{CO}} / k_{\mathrm{OD}+\mathrm{CO}}$ ratio at room temperature. The $\varepsilon{ }^{13} \mathrm{C}$ values at around $1 \mathrm{~atm}$ are also improved. The results are given and discussed in the following sections.

\section{RESULTS}

\section{A. Temperature effect}

The experimental values of the rate constants at 100 and $300 \mathrm{~K}$ in the low-pressure limit are about $1.1 \times 10^{-13}$ and $1.5 \times 10^{-13} \mathrm{~cm}^{3}$ molecule ${ }^{-1} \mathrm{~s}^{-1}$, respectively. ${ }^{6,12,13,17,40,66}$ The two parameters $E_{1}$ and $E_{2}$ used to adjust potential energies of $\mathrm{TS}_{a}$ and $\mathrm{TS}_{d}$ to obtain agreement with these two lowpressure rate constants are 0 and $340 \mathrm{~cm}^{-1}$, respectively, using the usual RRKM theory. When the nonstatistical modification is employed, they are instead 10 and $30 \mathrm{~cm}^{-1}$, respectively. (Since the low-pressure rates are independent of the parameter $\alpha$, we used them for this purpose.) The classical barrier with zero-point energy added for $\mathrm{TS}_{a}$ is about $280 \mathrm{~cm}^{-1}$ in both RRKM theory and the nonstatistical modification. For $\mathrm{TS}_{d}$ it is 965 and $655 \mathrm{~cm}^{-1}$, respectively. Although there are some differences between the barriers of the unmodified and modified RRKM theory, their temperaturedependent rate constants at low pressures shown in Fig. 2(a) are similar. The calculations in Figs. 2(a) and 3 show that the slopes of the calculated Arrhenius plot are comparable to those of the experiment, and the change in the slopes occurs in both cases between 300 and $500 \mathrm{~K}$. However, as seen in Fig. 3, the nonstatistical modification significantly improves 


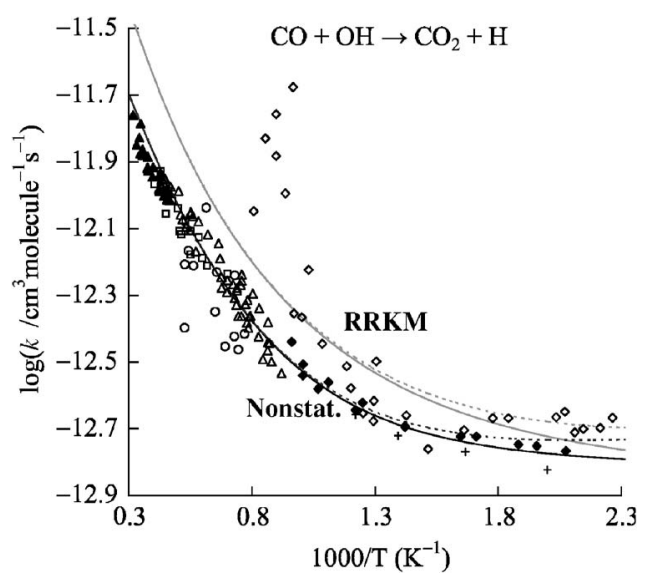

FIG. 3. Arrhenius plots for the $\mathrm{CO}+\mathrm{OH}$ reaction in the high-temperature region. The gray and black lines are obtained with the RRKM and the nonstatistical model, respectively. The solid lines are for the low-pressure limit and the dashed lines are at 785 torr Ar. The solid triangles are obtained by Lissianski et al. (Ref. 7). The open squares are for 1178-2379 torr obtained by Golden et al. (Ref. 17), open triangles for 682-1168 torr by Wooldridge et al. (Refs. 8,9), open circles for 682-1168 torr by Brabbs et al. (Ref. 10), open diamonds for 785 torr Ar by Jonah et al. (Ref. 4), and solid diamonds for 100 torr Ar by Ravishankara and Thompson (Ref. 6). The plus signs refer to the results at the low-pressure limit extrapolated by Fulle et al. (Ref. 5).

the agreement between experimental and calculated results of the rate constants for $\mathrm{CO}+\mathrm{OH}$ in the high-temperature region.

\section{B. Pressure effect}

Low- and high-pressure rate constants $k^{0}$ and $k^{\infty}$ were studied experimentally by Fulle et al. at various temperatures. ${ }^{5}$ Their fitted values are summarized in Table II, together with the present calculations and the step-down energy-transfer model. The effect of bath gases on the reaction of $\mathrm{CO}+\mathrm{OH}$ has been investigated for $\mathrm{He}, \mathrm{N}_{2}$, air, $\mathrm{CF}_{4}$, and $\mathrm{SF}_{6} \cdot{ }^{11,13,14,17,40}$ The calculated rate constants are compared with the experimental data in Fig. 4(a). The $\alpha$ values obtained by unmodified and modified RRKM theory are similar and are listed in Table III.

\section{C. $\mathrm{OD}$ and $\mathrm{OH}$}

Pressure-dependent rate constants were measured for the $\mathrm{OD}+\mathrm{CO}$ reaction with different bath gases by Paraskevopoulos and Irwin, ${ }^{41}$ Golden et al., ${ }^{17}$ and Frost et al. ${ }^{11}$ The three sets of measurements and the calculations for $\mathrm{He}, \mathrm{Ar}, \mathrm{N}_{2}$, air, $\mathrm{CF}_{4}$, and $\mathrm{SF}_{6}$ are compared in Fig. 4(b). For simplicity, the $\alpha$ 's for $\mathrm{OD}+\mathrm{CO}$ are assumed to be the same as those for $\mathrm{OH}+\mathrm{CO}$. The fitted curves for $\mathrm{OD}+\mathrm{CO}$ using the nonstatistical modification, shown in Fig. 5, agree well with experiment, except for $\mathrm{N}_{2}$, which is similar to the results of Golden et al. $^{17}$ and Senosiain et al. $^{27}$ and are discussed later. Unmodified RRKM theory underestimates the rate constant of $\mathrm{OD}+\mathrm{CO}$ at low pressures at room temperature, and so the fitted RRKM curves in Fig. 4(b) do not agree well in the low-pressure region. However, the nonstatistical modification significantly improves the agreement, as seen in Fig. 5.

The ratio $k_{\mathrm{OH}+\mathrm{CO}} / k_{\mathrm{OD}+\mathrm{CO}}$ calculated using RRKM theory is plotted in Fig. 6 as a function of the pressure of He. The theoretical results agree with the experimental data relatively well at pressures higher than 300-500 torr, but the nonstatistical modification significantly improves the rate constant ratios in the low-pressure region and agrees with the experimental data in the entire pressure region, as seen by the dashed line in Fig. 6. The pressure-dependent rate constants for the $\mathrm{OD}+\mathrm{CO}$ reaction with different bath gases calculated with the nonstatistical model in Fig. 5 also improve the agreement with experimental data in the low-pressure region. [cf. RRKM theory used in Fig. 4(b)].

The $\mathrm{OH}+\mathrm{CO}$ and $\mathrm{OD}+\mathrm{CO}$ systems in Fig. 2(a) show a marked difference in their dependence on temperature at low pressures and are calculated both for the RRKM theory and the nonstatistical modification. The $\mathrm{OD}+\mathrm{CO}$ rate is predicted to have a minimum value around $1000 / T=4$. Only Frost et al. appear to have studied the $\mathrm{OD}+\mathrm{CO}$ reaction at low pressures. ${ }^{11}$ The present calculation is in general agreement with their experimental results.

Jonah et al. measured the temperature dependence of the $\mathrm{OH}+\mathrm{CO}$ and $\mathrm{OD}+\mathrm{CO}$ rate constants at pressures $\sim 760$ torr at moderate and low temperatures. ${ }^{4}$ Fulle et al. did a similar experiment of the $\mathrm{OH}+\mathrm{CO}$ reaction at the lower-temperature

TABLE II. Comparison of the calculated $k^{0}$ 's and $k^{\infty}$ s at several temperatures with the extrapolated values by Fulle et al. (Ref. 5). The rate constants are in units of $10^{-13} \mathrm{~cm}^{3}$ molecule $\mathrm{e}^{-1} \mathrm{~s}^{-1}$.

\begin{tabular}{|c|c|c|c|c|c|c|}
\hline \multirow{2}{*}{$\begin{array}{c}T \\
(\mathrm{~K})\end{array}$} & \multicolumn{3}{|c|}{$k^{0}$} & \multicolumn{3}{|c|}{$k^{\infty}$} \\
\hline & RRKM & Nonstatistical & Expt. $^{\mathrm{a}}$ & RRKM & Nonstatistical & Expt. $^{a}$ \\
\hline 100 & 1.1 & 1.1 & $0.9^{\mathrm{b}}$ & 2.5 & 2.2 & $4.0^{\mathrm{b}}$ \\
\hline 200 & 1.4 & 1.4 & $1.3^{\mathrm{c}}$ & 7.3 & 6.8 & $7.0^{\mathrm{c}}$ \\
\hline 300 & 1.5 & 1.5 & 1.3 & 13.2 & 13.6 & 9.6 \\
\hline 400 & 1.7 & 1.6 & 1.4 & 20.2 & 19.5 & 12.6 \\
\hline 500 & 1.9 & 1.7 & 1.5 & 28.4 & 27.5 & 16.2 \\
\hline 600 & 2.2 & 1.8 & 1.7 & 37.8 & 36.9 & 20.3 \\
\hline 700 & 2.6 & 2.0 & $1.9^{\mathrm{d}}$ & 48.5 & 47.5 & $25.1^{\mathrm{d}}$ \\
\hline 800 & 3.1 & 2.3 & $2.2^{\mathrm{e}}$ & 60.3 & 59.3 & $30.0^{\mathrm{e}}$ \\
\hline $\begin{array}{l}\text { Results } \\
\text { Measu } \\
\text { Measur } \\
\text { Measu } \\
\text { Measur }\end{array}$ & $\begin{array}{l}\text { polated to } \\
98 \mathrm{~K} . \\
190 \mathrm{~K} . \\
717 \mathrm{~K} . \\
819 \mathrm{~K} .\end{array}$ & and $p=\infty$ by $F$ & & & & \\
\hline
\end{tabular}



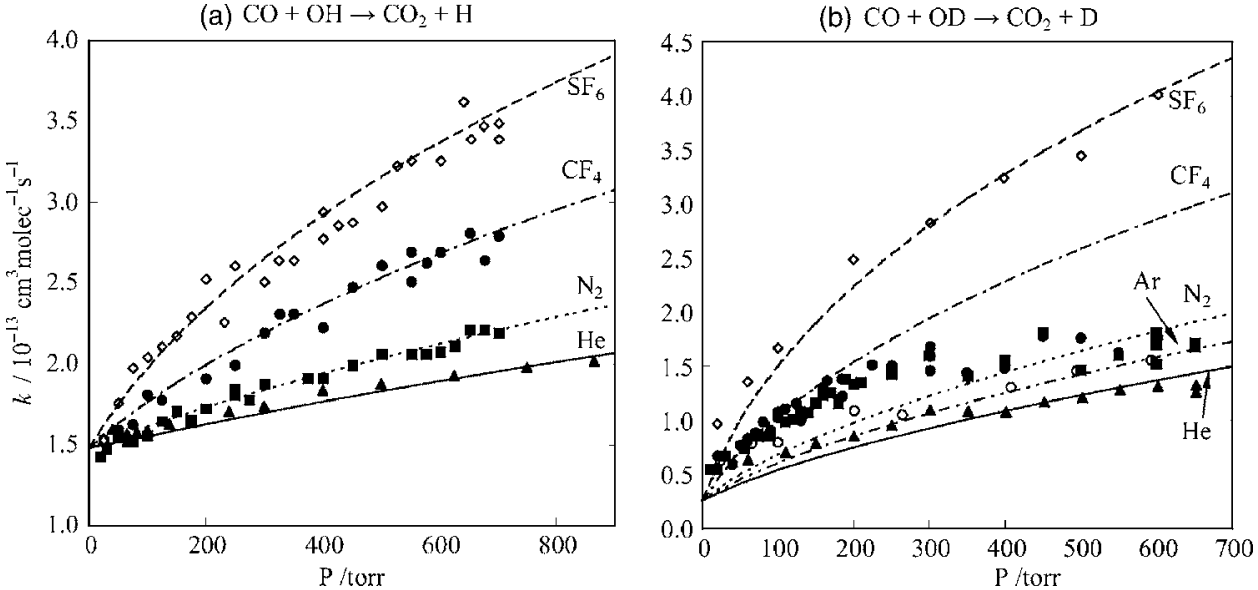

FIG. 4. Calculated and experimental pressure-dependent rate constants of (a) $\mathrm{CO}+\mathrm{OH}$ and (b) $\mathrm{CO}+\mathrm{OD}$ at $298 \mathrm{~K}$ for various bath gases. The RRKM method with the fitted energy-transfer parameter $\alpha$ listed in Table III is used in calculating rate constants. (a) The solid triangles are for He by Golden $e t$ al. (Ref. 17) and solid squares, solid circles, and open diamonds for $\mathrm{N}_{2}, \mathrm{CF}_{4}$, and $\mathrm{SF}_{6}$, respectively, by Paraskevopoulos and Irwin (Ref. 40). (b) The open circles and open diamonds are for $\mathrm{Ar}$ and $\mathrm{SF}_{6}$, respectively, by Golden et al. (Ref. 17). The solid triangle, solid squares, and solid circles are for $\mathrm{He}, \mathrm{N}_{2}$, and $\mathrm{CF}_{4}$, respectively, by Paraskevopoulos and Irwin (Ref. 40).

region. ${ }^{5}$ The temperature dependence of the calculated rate constants for both $\mathrm{OH}+\mathrm{CO}$ and $\mathrm{OD}+\mathrm{CO}$ reactions at 785 torr of Ar in Fig. 2(b) are similar in both RRKM theory and its nonstatistical modification models and are in good agreement with experiment.

\section{Kinetic isotope effect for carbon}

The isotopic fractionation of ${ }^{13} \mathrm{C}, \varepsilon{ }^{13} \mathrm{C}$, is defined as

$$
\varepsilon{ }^{13} \mathrm{C}=\left(\frac{{ }^{12} k}{{ }^{13} k}-1\right) \times 1000 \text { per mil, }
$$

where ${ }^{12} k$ and ${ }^{13} k$ are the rate constants for the reaction of ${ }^{12} \mathrm{CO}$ and ${ }^{13} \mathrm{CO}$ with $\mathrm{OH}$, respectively. Pressure-dependent $\varepsilon{ }^{13} \mathrm{C}$ 's from 75 to 840 torr at room temperature were measured by Stevens et al. ${ }^{29}$ Smit et al.,${ }^{30}$ and Röckmann et al. ${ }^{31}$ The data of Stevens et al. and Röckmann et al. show that $\varepsilon{ }^{13} \mathrm{C}$ depends slightly on bath gases. ${ }^{29,31}$ Our calculations for the pressure dependence of the $\varepsilon{ }^{13} \mathrm{C}$ values by both RRKM and the nonstatistical models, shown in Fig. 7, agree reasonably well with the experimental data. As the pressure is increased, the calculated $\varepsilon{ }^{13} \mathrm{C}$ values also increase and depend slightly on bath gases. We discuss these results in Sec. IV.

\section{DISCUSSION}

\section{A. The barriers at $\mathrm{TS}_{a}$ and $\mathrm{TS}_{d}$ \\ 1. RRKM theory}

As noted in Sec. III A two parameters $E_{1}$ and $E_{2}$ are needed to adjust the potential energies of $\mathrm{TS}_{a}$ and $\mathrm{TS}_{d}$, to fit the experimental values ${ }^{6,12,13,17,40,66}$ of the rate constants at 100 and $300 \mathrm{~K}$. The results of the barrier adjustments are consistent with recent previous estimates, the literature values varying from 100 to $380 \mathrm{~cm}^{-1}$ for $\mathrm{TS}_{a}$ and from 0 to $1000 \mathrm{~cm}^{-1}$ for $\mathrm{TS}_{d}{ }^{5,17-19,21,24}$ The fitted barriers for $\mathrm{TS}_{d}$ in the literature are more scattered than those for $\mathrm{TS}_{a}$ because of the difference in tunneling arising from large differences in imaginary frequencies at $\mathrm{TS}_{d}$. In most theoretical calculations, ${ }^{17-19,21,24,27}$ including the present, the exit channel barrier, $\Delta E_{d}$, including zero-point energy, is higher than that for the entrance channel, $\Delta E_{a}$, when the same calculational method is applied to both TSs.

TABLE III. The $\alpha$ values of several bath gases. The units are in $\mathrm{cm}^{-1}$.

\begin{tabular}{lccccc}
\hline \hline & & & $\begin{array}{c}\text { Zhu et al. } \\
(\text { Ref. 21) }\end{array}$ & $\begin{array}{c}\text { Golden } \text { et al. } \\
(\text { Ref. 22) }\end{array}$ & $\begin{array}{c}\text { Senosiain } \text { et al. } \\
\text { (Ref. 27) }^{\mathrm{b}}\end{array}$ \\
\hline $\mathrm{He}$ & 140 & 140 & 150 & $150^{\mathrm{c}}$ & 80 \\
$\mathrm{Ar}^{\mathrm{d}}$ & 190 & 190 & 450 & 300 & 110 \\
$\mathrm{~N}_{2}$ & 200 & 210 & 250 & $300^{\mathrm{e}}$ & $100^{\mathrm{f}}$ \\
$\mathrm{CF}_{4}$ & 300 & 310 & 450 & 680 & $160^{\mathrm{g}}$ \\
$\mathrm{SF}_{6}$ & 400 & 410 & 1000 & 800 & $190^{\mathrm{h}}$ \\
\hline \hline
\end{tabular}

\footnotetext{
${ }^{\mathrm{a}}$ The nonstatistical model is used.

${ }^{c} 180 \mathrm{~cm}^{-1}$ for OD+CO in $\mathrm{He}$.

${ }^{\mathrm{d}}$ Fitted to the data from $\mathrm{OD}+\mathrm{CO}$ reaction.

${ }^{\mathrm{e}} 480 \mathrm{~cm}^{-1}$ for $\mathrm{OD}+\mathrm{CO}$ in $\mathrm{N}_{2}$.

${ }^{\mathrm{f}} 140 \mathrm{~cm}^{-1}$ for $\mathrm{OD}+\mathrm{CO}$ in $\mathrm{N}_{2}$.

${ }^{\mathrm{g}} 150 \mathrm{~cm}^{-1}$ for $\mathrm{OD}+\mathrm{CO}$ in $\mathrm{CF}_{4}$

$200 \mathrm{~cm}^{-1}$ for $\mathrm{OD}+\mathrm{CO}$ in $\mathrm{SF}_{6}$.
}

${ }^{\mathrm{b}}$ The pressure effect is calculated using the exponential down model. 


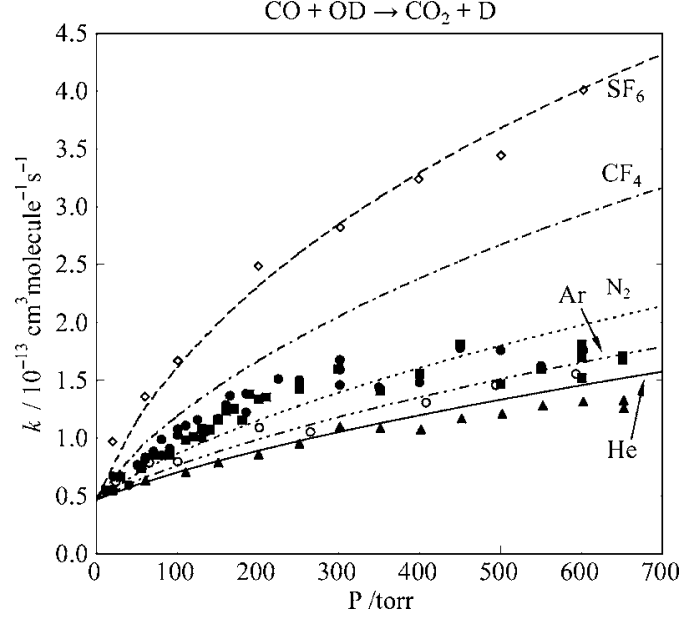

FIG. 5. Comparison of the experimental pressure-dependent rate constants of $\mathrm{CO}+\mathrm{OD}$ at $298 \mathrm{~K}$ for various bath gases with the calculated rate constants using the nonstatistical modification. The energy-transfer parameter $a$ assumed is listed in Table III. The open circles and open diamonds are for $\mathrm{Ar}$ and $\mathrm{SF}_{6}$, respectively, obtained by Golden et al. (Ref. 17) and the solid triangle, solid squares, and solid circles are for $\mathrm{He}, \mathrm{N}_{2}$, and $\mathrm{CF}_{4}$, respectively, by Paraskevopoulos and Irwin (Ref. 40).

Because of the large width and low barrier of $\mathrm{TS}_{a}$, tunneling through $\mathrm{TS}_{a}$ at the low-pressure limit is important only at temperatures below $400 \mathrm{~K}$. The calculated tunneling effects at $\mathrm{TS}_{a}$ increase the rate constant by about $10 \%$ in the low-pressure limit for a temperature of $400 \mathrm{~K}$ and less at higher temperatures. When any tunneling at $\mathrm{TS}_{a}$ is neglected, the reaction rate at room temperature in the low-pressure limit is less by about $20 \%$. This effect is much smaller than that at $\mathrm{TS}_{d}$, where the neglect of tunneling reduces the rate constant by a factor of 20 .

The rate constants calculated with variation of rotational constants along the minimum reaction path near both TSs reduced the rate constants at low pressure by less than $1 \%$ at room temperature, as compared with fixing the position of $\mathrm{TS}_{a}$ at the local potential-energy maximum along this reaction coordinate. In the low-pressure limit the rate constant

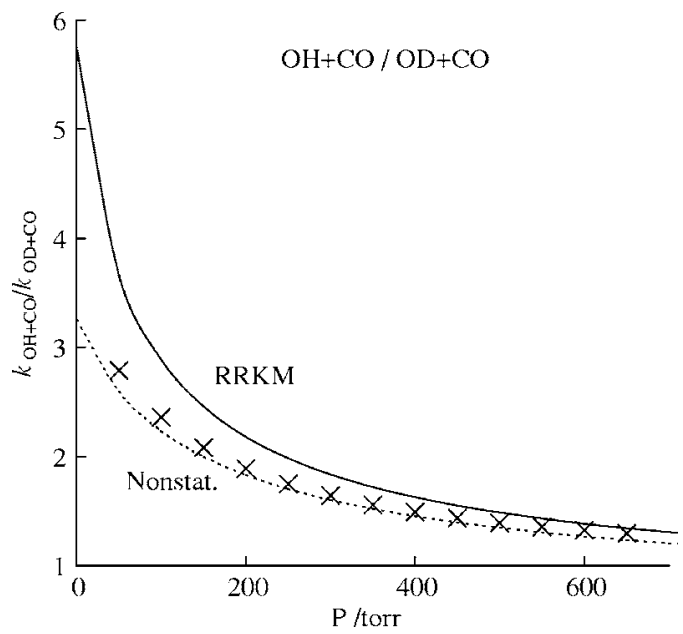

FIG. 6. Comparison of calculated and experimental results for the H/D kinetic isotope effect as a function of pressure at $300 \mathrm{~K}$. The experimental data (X's) are taken from a fit to Paraskevopoulos' results. The solid line is calculated using the conventional RRKM theory, and the dashed line is obtained using the nonstatistical modification.

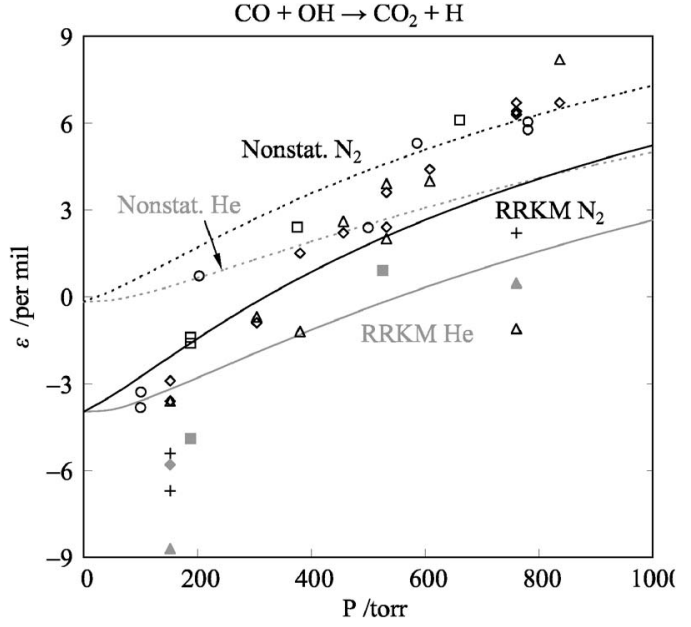

FIG. 7. The $\varepsilon{ }^{13} \mathrm{C}$ values for the system of $\mathrm{CO}+\mathrm{OH}$ given as a function of the total pressure at room temperature. The solid lines are calculated using the conventional RRKM theory, and the dashed line is obtained with the nonstatistical model. The black and gray lines indicate the pressure dependence in $\mathrm{N}_{2}$ and $\mathrm{He}$ gases, respectively. The open circles are obtained for $\mathrm{N}_{2}$ by Smit et al. (Ref. 30). The gray solid and black open squares are obtained in $\mathrm{He}$ and $\mathrm{N}_{2}$ (or $\mathrm{N}_{2}+\mathrm{O}_{2}$ ), respectively, by Röckmann et al. (Ref. 31). The gray solid triangles, black open triangle, open diamond, and plus symbols are obtained in Ar, air (by measuring products), air, and $\mathrm{O}_{2}$, respectively, by Stevens et al. (Ref. 29).

was reduced by $5 \%$ and $10 \%$ at 1000 and $2500 \mathrm{~K}$, respectively. At high pressures this effect of varying the rotational constants along the reaction coordinate reduced the rate constant by $10 \%$ at $1000 \mathrm{~K}$ and $20 \%$ at $2500 \mathrm{~K}$. The variational effects by Senosiain et al. $^{27}$ reduced the rate constants by $23 \%$ at $1000 \mathrm{~K}$ and $42 \%$ at $2500 \mathrm{~K}$ at low pressures, and by $11 \%$ at $1000 \mathrm{~K}$ and $21 \%$ at $2500 \mathrm{~K}$ at high pressures. The decrease is smaller in our calculations, presumably due to their taking into account the changing hindering rotation of $\mathrm{OH}$ and $\mathrm{CO}$ in $\mathrm{TS}_{a}$ along the reaction path.

\section{Nonstatistical modification}

The barrier of $\mathrm{TS}_{a}$ in the modification is similar to that used for the usual theory, reflecting the small sensitivity of the rate to $\mathrm{TS}_{a}$. The barrier of $\mathrm{TS}_{d}$ now needed is about $300 \mathrm{~cm}^{-1}$ less than before. This lowering compensates for the constraint placed on the intramolecular energy transfer in the $\mathrm{HOCO}^{*}$ when it passes through the $\mathrm{TS}_{d}$ in this nonstatistical modification.

\section{B. Non-Arrhenius behavior}

\section{RRKM theory}

The strongly non-Arrhenius behavior of the $\mathrm{CO}+\mathrm{OH}$ reaction in Fig. 2 was observed in many earlier studies, both experimentally ${ }^{5,6,11-13,15}$ and theoretically. ${ }^{17,20-22,25}$ The experimental rate constants are slightly temperature dependent at low pressures in the temperature range 100-500 K, but increase steeply at higher temperatures. ${ }^{5,6,11}$ Because the barriers to form products $\left(\mathrm{H}+\mathrm{CO}_{2}\right)$ or revert to reactants $(\mathrm{OH}$ $+\mathrm{CO}$ ) from $\mathrm{HOCO}^{*}$ are similar, the competition between $k_{-1}$ in Eq. (1) and $k_{2}$ in Eq. (2) for HOCO* disappearance serves to explain the change of slope of $\ln k$ versus $1 / T$ of the reaction in Fig. 2(a); in the present calculations at high tem- 
peratures the $k_{-1}$ in Eq. (1) is much larger than the $k_{2}$ in Eq. (2). So the barrier in the exit channel $\mathrm{TS}_{d}$ then dominates the rate. However, at temperatures below $\sim 500 \mathrm{~K} k_{-1}$ and $k_{2}$ are comparable. Due to a large tunneling through $\mathrm{TS}_{d}$ at lower energies, $k_{2} / k_{-1}$ ultimately increases as the temperature is decreased and so the contribution to the barrier from the rate at the entrance channel $\mathrm{TS}_{a}$ increases. In summary, the change in slope in Fig. 2(a) is due to the similar barrier heights of both entrance and exit channels together with a large tunneling effect in the exit channel $\mathrm{TS}_{d}$.

\section{Nonstatistical modification}

The results calculated using the modification are similar to those obtained with the unmodified theory. However, as seen in Fig. 3, the modification describes the experiments at the high temperatures better than before.

\section{Pressure effect}

\section{RRKM theory}

The calculated low- and high-pressure rate constants, $k^{0}$ and $k^{\infty}$, at the various temperatures listed in Table II, were compared with the extrapolated experimental values of Fulle et al. ${ }^{5}$ As mentioned earlier, the calculated rate constants in the low-pressure limit are very similar to the extrapolated experimental values. The rate constants at the high-pressure limit are largely controlled by the properties of $\mathrm{TS}_{a}$, and the extent of agreement with the extrapolated experimental values by Fulle et al. ${ }^{5}$ in the high-pressure limit is seen in Table II. Any difference may reflect a shortcoming of the calculation of $\mathrm{TS}_{a}$.

The effect of bath gases on the reaction of $\mathrm{CO}+\mathrm{OH}$ has been studied for $\mathrm{He}, \mathrm{N}_{2}$, air, $\mathrm{CF}_{4}$, and $\mathrm{SF}_{6} \cdot{ }^{11,13,14,17,40}$ It has been repeatedly documented that polyatomic bath gases are better energy-transfer agents than monatomic gases. Possible reasons include higher densities of intramolecular energy states for the collisional energy transfer, larger collision radii, and more attractive interactions leading to a closer and so more steeply repulsive interaction. The fitted energy-transfer parameter $\alpha$ for $\mathrm{He}, \mathrm{Ar}, \mathrm{N}_{2}, \mathrm{CF}_{4}$, and $\mathrm{SF}_{6}$ is $140,190,200$, 300 , and $400 \mathrm{~cm}^{-1}$, respectively. The calculated rate constants and the experimental data are compared in Fig. 4(a). The $\alpha$ values listed in Table III are close to the fitted $\alpha$ values of Zhu et al. ${ }^{21}$ and Senosiain et al., ${ }^{22}$ especially for monatomic and diatomic gases, but are larger than the fitted values of Senosiain et al. ${ }^{27}$ Strictly speaking the $\alpha$ values are not exactly equivalent since the exponential down model is used by all other groups. In the results of other groups and ours the somewhat larger deviations of the $\alpha$ values for the polyatomic gases may arise from the different pressure models employed.

The pressure-dependent measurements of OD reacting with $\mathrm{CO}$ in various bath gases, $\mathrm{He}, \mathrm{Ar}, \mathrm{N}_{2}$, air, $\mathrm{CF}_{4}$, and $\mathrm{SF}_{6}, 11,17,41$ are compared in Fig. 4(b) with calculations using the unmodified RRKM theory. Assuming the $\alpha$ 's for OD $+\mathrm{CO}$ to be similar to those used for $\mathrm{OH}+\mathrm{CO}$, the fitted curves for $\mathrm{OD}+\mathrm{CO}$ are in general agreement with experiment. The results indicate that $\alpha$ depends not only on the bath gas but also on whether the isotope is D or H. Senosiain et al. ${ }^{22,27}$ optimized their calculations to agree with the experimental data by adjusting the $\alpha$ values for both $\mathrm{OD}+\mathrm{CO}$ and $\mathrm{OH}+\mathrm{CO}$. Their $\alpha$ 's for $\mathrm{OD}+\mathrm{CO}$ are somewhat higher than those for $\mathrm{OH}+\mathrm{CO}$, but the difference is small, except for $\mathrm{N}_{2}$, for which the results are similar to ours. For simplicity, the same $\alpha$ value for the $\mathrm{C}$-isotope-substituted $\mathrm{OH}+\mathrm{CO}$ reactions in each bath gas is assumed in the study of the kinetic C-isotopic effect discussed in Sec. IV F.

\section{Nonstatistical modification}

The $k^{0}$ values at high temperatures obtained with the RRKM modified theory are smaller than those obtained with conventional theory and are closer to the extrapolated experimental results. The $k^{\infty}$ values are similar in both treatment, because they are mainly determined by the properties of $\mathrm{TS}_{a}$, which is treated in the same way in both models. The energytransfer parameter $\alpha$ for various bath gases by both models are similar and are listed in Table III. The nonstatistical theory improves the agreement of the pressure dependence of $\mathrm{OD}$ reacting with $\mathrm{CO}$ in various bath gases significantly, especially for the extrapolated values at zero pressure, as shown in Fig. 5. The most important improvement arising from the nonstatistical model is in the plot of $k_{\mathrm{OH}+\mathrm{CO}} / k_{\mathrm{OD}+\mathrm{CO}}$ ratios versus pressure, especially at lower pressures, as in Fig. 6. In that figure, the large discrepancy between experiment and the conventional RRKM theory is clear. This discrepancy with conventional RRKM theory was also seen in Fig. 9 of Ref. 27 and is now removed by the nonstatistical modification (Fig. 6). The robustness of this result is shown in Appendix A 4 (Fig. 10).

\section{Negative temperature effect in $O D+C O$ \\ 1. RRKM theory}

The calculated rate constants for OD $+\mathrm{CO}$ in Fig. 2(a) display a minimum around $250 \mathrm{~K}$. Only Frost et al. appear to have studied the $\mathrm{OD}+\mathrm{CO}$ reaction as a function of temperature at low pressures. ${ }^{11}$ In their study at 178,216 , and $295 \mathrm{~K}$, Fig. 2(a), they observed nearly temperature-independent reaction rates. Their RRKM calculations also showed a slight decrease in rate in going from 80 to $300 \mathrm{~K}$. There is general agreement between the experimental and calculated results.

The relatively large negative temperature effects observed in the OD+CO reaction, shown in Fig. 2(a), can be explained by the lowered barrier at $\mathrm{TS}_{a}$ and the increased height of the $\mathrm{TS}_{d}$ barrier in $\mathrm{OD}+\mathrm{CO}$ relative to that in $\mathrm{OH}$ $+\mathrm{CO}$. The energy with the zero-point corrections of $\mathrm{TS}_{a}$ in $\mathrm{OD}+\mathrm{CO}$ is around $150 \mathrm{~cm}^{-1}$ and that of $\mathrm{TS}_{d}$ is around $1320 \mathrm{~cm}^{-1}$. Although the value of the imaginary frequency of $\mathrm{OD}$ at $\mathrm{TS}_{d}$ is smaller than that of $\mathrm{OH}$, the barrier change increases the tunneling window (energy difference between $\mathrm{TS}_{d}$ and $\mathrm{TS}_{a}$ ) by about $500 \mathrm{~cm}^{-1}$ in $\mathrm{OD}+\mathrm{CO}$. The decreased barrier in the entrance channel allows the formation of more intermediates at low temperatures. At low pressures, the intermediates can only tunnel through $\mathrm{TS}_{d}$ to products or revert to reactants. The number of states is approximately independent of temperature, but the partition function of the collision pair decreases as temperatures increase. From our calculations in Fig. 2(a), the negative temperature effect is signifi- 
cant at temperatures lower than $250 \mathrm{~K}$. The experiments on $\mathrm{OD}+\mathrm{CO}$ at low pressures and temperatures would permit a test of the prediction of a negative temperature effect in the present calculation.

When different $a b$ initio theories are used there is a difference of imaginary frequency at $\mathrm{TS}_{d}$ in various force constants. As a result, the temperature where the minimum in the calculated rate constant occurs is spread from 200 to $400 \mathrm{~K}$, as shown in Appendix A 2, the higher temperature occurs with the larger value of the imaginary frequencies. The studies on $\mathrm{OD}+\mathrm{CO}$ at low pressures and low temperatures would help determine better the value of the imaginary frequency at $\mathrm{TS}_{d}$ and so determine more precisely the magnitude of tunneling effects.

\section{Nonstatistical modification}

Comparing the Arrhenius plot of the $\mathrm{OD}+\mathrm{CO}$ reaction at low pressures for the unmodified and modified theories, the former has a weaker temperature dependence in the lowtemperature region. This result is consistent with the results in the experiment of Frost et al. There are only two measurements of the rate constants below $250 \mathrm{~K}$. More measurements at low temperatures would permit a test of the trend predicted in Fig. 2(a).

\section{E. $\mathrm{OH}$ and OD}

\section{RRKM theory}

In the measurements of Paraskevopoulos and Irwin, ${ }^{40}$ Frost et al., ${ }^{11}$ and Golden et al., ${ }^{17}$ the pressure-dependent kinetic H/D isotope effect is given at about $300 \mathrm{~K}$. At low pressures their experimental values for $k_{\mathrm{OH}+\mathrm{CO}} / k_{\mathrm{OD}+\mathrm{CO}}$ are 3.6, 2.7, and 2.3, respectively. This kinetic effect can be understood in terms of tunneling, together with the zero-point energy difference of $\mathrm{TS}_{a}$ and $\mathrm{TS}_{d}$. Compared with the ratios in the data of Paraskevopoulos and Irwin, the ratio $k_{\mathrm{OH}+\mathrm{CO}} / k_{\mathrm{OD}+\mathrm{CO}}$ calculated using the unmodified theory, the solid line in Fig. 6, significantly overestimates it at pressures below 500 torr, but is comparable with experiments at higher pressures. The robustness of this result is seen later in Appendix A.

Jonah et al. measured the rates of $\mathrm{OH}+\mathrm{CO}$ and $\mathrm{OD}$ $+\mathrm{CO}$ from 340 to $1250 \mathrm{~K}$ at 1 atm of Ar and 15 torr of water vapor. ${ }^{4}$ Both rates have minima around $600 \mathrm{~K}$ [Fig. 2(b)]. This negative dependence on temperature was also observed by Fulle et al. ${ }^{5}$ in the rates of $\mathrm{OH}+\mathrm{CO}$ from 91 to $288 \mathrm{~K}$ at 750 torr of He. The rate constants measured by the latter group showed a maximum around $170 \mathrm{~K}$. Our calculations in Fig. 2(b) for both $\mathrm{OH}+\mathrm{CO}$ and $\mathrm{OD}+\mathrm{CO}$ reactions at 785 torr of Ar are close to their results. The minimum rate of $\mathrm{OH}$ and OD occurs at about 400 and $500 \mathrm{~K}$, respectively, which are slightly lower than the measured values. The calculated negative temperature dependence of the $\mathrm{CO}+\mathrm{OH}$ reaction rate between 200 and $400 \mathrm{~K}$ has a maximum around $160 \mathrm{~K}$, which is close to the maximum in the measurements of Fulle et al.

\section{Nonstatistical modification}

When the intramolecular energy-transfer restriction is introduced using the modified theory, the agreement of the rate constant ratios at the low-pressure region is significantly improved, as seen by the dashed line in Fig. 6. The modified theory also improves agreement with experiment for the pressure dependence of the low-pressure rate constants of $\mathrm{OD}+\mathrm{CO}$ as in Fig. 5. The temperature dependence of the rate constants at pressures $\sim 1 \mathrm{~atm}$ are similar to these in the unmodified theory and in the experiment. At temperatures higher than $1000 \mathrm{~K}$, the rate constants in Fig. 3 obtained using the modified theory agree better with the experiment than before and are lower than the conventional RRKM result by about $60 \%$.

The calculations for the unmodified theory tend to underestimate the rate constants of $\mathrm{OD}+\mathrm{CO}$ in the lowpressure region, perhaps because any difference in the energy-transfer ability between $\mathrm{HOCO}^{*}$ and $\mathrm{DOCO}^{*}$ is not considered. The vibrational frequency of the OD stretching in DOCO, about $2700 \mathrm{~cm}^{-1}$, is much less than the $\mathrm{OH}-$ stretching frequency. Accordingly, the energy transfer between the OD stretching and other modes in energetic DOCO $^{*}$ may well be easier than in HOCO* ${ }^{*}$ In the nonstatistical modification, the relation between the energy-transfer parameter $\xi$ in HOCO and that in DOCO is simply assumed to be

$$
\xi_{D}=\frac{\nu}{\nu_{D}} \xi
$$

where $\nu$ is the $\mathrm{OH}(\mathrm{OD})$ stretching frequency in the intermediate, the subscript $D$ and no subscript indicating the DOCO and HOCO systems, respectively. Equation (10) implies that the energy redistribution in the energetic DOCO is faster than that in HOCO. In counting the number of states for $\mathrm{TS}_{d}$, with a tunneling correction using Eq. (C2), the range of integration used for DOCO is about 30\% larger than that for HOCO due to the $\nu_{D}$ in Eq. (10) being smaller than $\nu$.

\section{F. Kinetic isotope effect for carbon \\ 1. RRKM theory}

The reaction at atmospheric pressure was found to favor a positive $\varepsilon{ }^{13} \mathrm{C}$ by 6 per mil, while negative values were observed at pressures below $\sim 300$ torr. These experimental data also show that $\varepsilon{ }^{13} \mathrm{C}$ depends slightly on the bath gas. ${ }^{29,31}$ The values in monatomic gases, such as $\mathrm{He}$ or $\mathrm{Ar}$, are lower than those in diatomic gases, such as air, $\mathrm{O}_{2}$, and $\mathrm{N}_{2}$. Our calculations in Fig. 7 for $\varepsilon{ }^{13} \mathrm{C}$ agree reasonably well with these data. The calculated $\varepsilon{ }^{13} \mathrm{C}$ at low pressures is negative, around -4 per mil. As the pressure increases, the calculated $\varepsilon{ }^{13} \mathrm{C}$ increases to positive values, similar to the pressure dependence observed in the experiment. Although the values of collision stabilization energy, the $\alpha$ 's for $\mathrm{He}$ and $\mathrm{N}_{2}$ are different, the trend in pressure dependence of $\varepsilon{ }^{13} \mathrm{C}$ in Fig. 7 is similar. As pressure increases, the $\varepsilon{ }^{13} \mathrm{C}$ in $\mathrm{N}_{2}$ increases faster than in $\mathrm{He}$, but the difference is small.

The calculated negative $\varepsilon{ }^{13} \mathrm{C}$ at low pressures can be understood in terms of the higher density of the vibrational and rotational states for heavier isotopic molecules. The 
TABLE IV. Parameters for fitting the rate constants at 100 and $300 \mathrm{~K}$ in the low-pressure limit for various PES's and $a b$ initio methods. ${ }^{a}$ All units are $\mathrm{cm}^{-1}$.

\begin{tabular}{|c|c|c|c|c|c|c|c|c|}
\hline \multirow{2}{*}{$\begin{array}{l}\text { PES } \\
a b \text { initio }\end{array}$} & \multicolumn{4}{|c|}{ G2M } & \multicolumn{4}{|c|}{ LTSH } \\
\hline & DFT-CC & DFT-MP & $\mathrm{CC}$ & MP2 & DFT-CC & DFT-MP & $\mathrm{CC}$ & MP2 \\
\hline$E_{1}$ & -10 & -10 & 0 & 10 & -280 & -280 & -270 & -260 \\
\hline \multirow[t]{2}{*}{$E_{2}$} & 60 & 10 & 340 & 580 & 330 & 290 & 620 & 850 \\
\hline & \multicolumn{8}{|c|}{$\mathrm{OH}+\mathrm{CO}$} \\
\hline$\Delta E_{a}$ & 269 & 349 & 275 & 359 & 273 & 353 & 280 & 363 \\
\hline$\Delta E_{d}$ & 714 & 664 & 965 & 1318 & 704 & 664 & 964 & 1308 \\
\hline$\nu_{a}^{i}$ & $312 i$ & $449 i$ & $312 i$ & $449 i$ & $312 i$ & $449 i$ & $312 i$ & $449 i$ \\
\hline \multirow[t]{2}{*}{$\nu_{d}^{i}$} & $1526 i$ & $1526 i$ & $2126 i$ & $3176 i$ & $1526 i$ & $1526 i$ & $2126 i$ & $3176 i$ \\
\hline & \multicolumn{8}{|c|}{$\mathrm{OD}+\mathrm{CO}$} \\
\hline$\Delta E_{a}$ & 135 & 194 & 150 & 221 & 139 & 199 & 154 & 226 \\
\hline$\Delta E_{d}$ & 1067 & 1017 & 1322 & 1665 & 1057 & 1017 & 1322 & 1655 \\
\hline$\nu_{a}^{i}$ & $310 i$ & $447 i$ & $310 i$ & $447 i$ & $310 i$ & $447 i$ & $310 i$ & $447 i$ \\
\hline$\nu_{d}^{i}$ & $1219 i$ & $1219 i$ & $1686 i$ & $2547 i$ & $1219 i$ & $1219 i$ & $1686 i$ & $2547 i$ \\
\hline
\end{tabular}

pressure dependence of $\varepsilon{ }^{13} \mathrm{C}$ can be explained in terms of the difference of vibrational energies at the TSs and of the collision frequencies, $\omega$, for the ${ }^{12} \mathrm{C}$ and ${ }^{13} \mathrm{C}$ intermediates; due to the lower barrier and higher number of states in both $\mathrm{TS}_{a}$ and $\mathrm{TS}_{d}$ when ${ }^{13} \mathrm{C}$ is substituted for ${ }^{12} \mathrm{C},{ }^{13} k$ is larger than ${ }^{12} k$ in the low-pressure region, causing $\varepsilon{ }^{13} \mathrm{C}$ to be negative in the present theory. The collision frequencies are proportional to $\mu^{-1 / 2}$, where $\mu$ is the reduced mass of the bath gas and $\mathrm{HOCO}^{*}$. As the pressure is increased the rate of collision stabilization of intermediates is larger due to the larger collision frequency. Therefore, the presently calculated $\varepsilon{ }^{13} \mathrm{C}$ values in Fig. 7 vary from slightly negative at low pressures to about +5 per mil at 1000 torr, which is similar to the experimental data. The collision factor can introduce a maximum of +7 per mil when the bath gas is $\mathrm{N}_{2}$ and the rate is proportional to the collision frequency.

\section{Nonstatistical modification}

Our calculations in Fig. 7 for $\varepsilon{ }^{13} \mathrm{C}$ in both the unmodified and the modified theory agree reasonably well with the experimental data. The $\varepsilon{ }^{13} \mathrm{C}$ calculated using the modified theory are a little larger than the values obtained before. It increases from -4 per mil to about 0 per mil at 100 torr, which is higher than the independent experimental results of Stevens et al. ${ }^{29}$ and Smit et al. ${ }^{30}$ given in Fig. 7. Even though the values obtained using the model in the low-pressure region tend to overestimate the carbon fractionation, as compared with experiment, they are still in good overall agreement with the data, especially for pressures higher than 500 torr. Similar to the results obtained for the pressure dependence of the $\varepsilon{ }^{13} \mathrm{C}$ values of two bath gases with the unmodified theory, the values in $\mathrm{N}_{2}$ using the modified theory increase faster than those in $\mathrm{He}$, again in agreement with experiments.

\section{CONCLUSIONS}

The use of a nonstatistical modification of the RRKM theory significantly improves the agreement with experiment for (1) the pressure-dependent $k_{\mathrm{OH}+\mathrm{CO}} / k_{\mathrm{OD}+\mathrm{CO}}$ ratio, (2) the pressure dependence of the $\mathrm{OD}+\mathrm{CO}$ reaction rate, and (3) the non-Arrhenius behavior at high temperatures. In (1) a major discrepancy between experiment and theory has been removed, assuming the validity of the nonstatistical effect. A negative temperature effect at low temperatures in the OD $+\mathrm{CO}$ reaction is predicted in both unmodified and modified RRKM theories. The measured $\varepsilon{ }^{13} \mathrm{C}$ effect is very small and pressure dependent. The calculations with unmodified and modified RRKM theories are in reasonable agreement with ${ }^{13} \mathrm{C}$ rate, considering the extremely small magnitude of the effect (from -4 per mil at low pressures to 6 per mil at $\sim 1 \mathrm{~atm})$.

\section{ACKNOWLEDGMENTS}

It is a pleasure to acknowledge the support of this research by the National Science Foundation. We also thank Dr. Muckerman for providing the F matrix for the structures in their paper, ${ }^{18}$ which were used to check the accuracy of rate constant calculation with our previous vibrational frequencies.

\section{APPENDIX A: RESULTS FOR DIFFERENT PES'S}

Calculations with different and less accurate force constant methods were used to test the sensitivity of certain aspects of the calculations and are discussed in this Appendix. The results for the $k_{\mathrm{OH}+\mathrm{CO}} / k_{\mathrm{OD}+\mathrm{CO}}$ ratios between 200 and 800 torr and for the non-Arrhenius effect and the pressure effect below 1000 torr all show a robustness toward the different calculations. Apart from the transition state structure of the entrance channel $\left(\mathrm{TS}_{a}\right),{ }^{67}$ the vibrational frequencies and rotational constants of all structures for the various isotopes were calculated by three methods in this comparison, 
TABLE V. $k^{0}$ 's and $k^{\infty}$ s at temperatures obtained from values extrapolated to $p=0$ by Fulle $e t$ al. (Ref. 5) and calculated with various PESs. The rate constants have units of $10^{-13} \mathrm{~cm}^{3}$ molecule ${ }^{-1} \mathrm{~s}^{-1}$.

\begin{tabular}{|c|c|c|c|c|c|c|c|c|c|}
\hline \multirow{2}{*}{$\begin{array}{l}\text { PES } \\
a b \text { initio }\end{array}$} & \multicolumn{4}{|c|}{$\mathrm{G} 2 \mathrm{M}$} & \multicolumn{4}{|c|}{ LTSH } & \multirow[b]{2}{*}{ Expt. $^{\mathrm{a}}$} \\
\hline & DFT-CC & DFT-MP & $\mathrm{CC}$ & MP2 & DFT-CC & DFT-MP & $\mathrm{CC}$ & MP2 & \\
\hline & \multicolumn{9}{|c|}{$k^{0}$} \\
\hline $100 \mathrm{~K}$ & 1.1 & 1.1 & 1.1 & 1.1 & 1.1 & 1.1 & 1.1 & 1.0 & $0.9^{\mathrm{b}}$ \\
\hline $200 \mathrm{~K}$ & 1.3 & 1.3 & 1.4 & 1.3 & 1.3 & 1.2 & 1.3 & 1.3 & $1.3^{\mathrm{c}}$ \\
\hline $300 \mathrm{~K}$ & 1.5 & 1.5 & 1.5 & 1.5 & 1.5 & 1.5 & 1.5 & 1.5 & 1.3 \\
\hline $400 \mathrm{~K}$ & 1.7 & 1.8 & 1.7 & 1.6 & 1.7 & 1.8 & 1.6 & 1.6 & 1.4 \\
\hline $500 \mathrm{~K}$ & 2.0 & 2.1 & 1.9 & 1.8 & 2.1 & 2.1 & 1.9 & 1.8 & 1.5 \\
\hline $600 \mathrm{~K}$ & 2.4 & 2.5 & 2.2 & 1.9 & 2.5 & 2.5 & 2.2 & 2.0 & 1.7 \\
\hline $700 \mathrm{~K}$ & 2.9 & 3.0 & 2.6 & 2.2 & 3.0 & 3.0 & 2.6 & 2.2 & $1.9^{\mathrm{d}}$ \\
\hline \multirow[t]{2}{*}{$800 \mathrm{~K}$} & 3.5 & 3.6 & 3.1 & 2.5 & 3.5 & 3.6 & 3.1 & 2.5 & $2.2^{\mathrm{e}}$ \\
\hline & \multicolumn{9}{|c|}{$k^{\infty}$} \\
\hline $100 \mathrm{~K}$ & 2.9 & 1.8 & 2.5 & 1.5 & 2.7 & 1.8 & 2.4 & 1.5 & $4.0^{\mathrm{b}}$ \\
\hline $200 \mathrm{~K}$ & 8.0 & 4.5 & 7.3 & 4.0 & 7.8 & 4.3 & 7.1 & 3.9 & $7.0^{\mathrm{c}}$ \\
\hline $300 \mathrm{~K}$ & 14.1 & 8.0 & 13.2 & 7.4 & 13.9 & 7.9 & 13.0 & 7.2 & 9.6 \\
\hline $400 \mathrm{~K}$ & 21.5 & 12.4 & 20.2 & 11.5 & 21.2 & 12.2 & 19.9 & 11.3 & 12.6 \\
\hline $500 \mathrm{~K}$ & 30.1 & 17.5 & 28.4 & 16.3 & 29.7 & 17.4 & 28.0 & 16.2 & 16.2 \\
\hline $600 \mathrm{~K}$ & 40.0 & 23.5 & 37.8 & 21.9 & 39.6 & 23.3 & 37.5 & 21.8 & 20.3 \\
\hline $700 \mathrm{~K}$ & 51.2 & 30.2 & 48.5 & 28.3 & 50.8 & 30.0 & 48.1 & 28.1 & $25.1^{\mathrm{d}}$ \\
\hline $800 \mathrm{~K}$ & 63.7 & 37.7 & 60.3 & 35.4 & 63.3 & 37.5 & 59.9 & 35.2 & $30.0^{\mathrm{e}}$ \\
\hline
\end{tabular}

${ }^{\mathrm{a}}$ Extrapolated results to $p=0$ and $p=\infty$ by Fulle et al. (Ref. 5).

${ }^{\mathrm{b}}$ Measured at $98 \mathrm{~K}$.

c measured at $190 \mathrm{~K}$.

${ }^{\mathrm{d}}$ Measured at $717 \mathrm{~K}$.

${ }^{\mathrm{e}}$ Measured at $819 \mathrm{~K}$.

$\operatorname{CCSD}(\mathrm{T})$ with 6-31G $(d, p)$, B3LYP with cc-pVTZ, and MP2 with $6-31++\mathrm{G}(d, p)$. The properties of $\mathrm{TS}_{a}$ are obtained only from the results of MP2 or CC. The acronym DFT will denote the calculation by B3LYP. DFT-MP will denote the calculations combining the structure data of $\mathrm{TS}_{a}$ from MP2 and the other statures from B3LYP, while DFT-CC is similar but with the data for $\mathrm{TS}_{a}$ obtained from $\operatorname{CCSD}(\mathrm{T})$. The LTSH potential, given by Lakin et al. ${ }^{24}$ involves an analytical function based on recent high-level ab initio methods and was also used to explore the robustness.

\section{Temperature and pressure effects}

Some robustness is expected to occur partly because there are two adjustable parameters $E_{1}$ and $E_{2}$ of the potential energy of $\mathrm{TS}_{a}$ and $\mathrm{TS}_{d}$ determined from the two rate constants. These $E_{1}$ and $E_{2}$ adjustments are listed for each specific PES in Table IV. Although the parameters differ between G2M and LTSH, the resulting classical barriers (i.e., no tunneling) with zero-point corrections of $\mathrm{TS}_{a}$ and $\mathrm{TS}_{d}$ are similar at the same $a b$ initio level. All the barriers of $\mathrm{TS}_{a}$ with zero-point corrections in our fitted results agree well with the recent estimates derived from kinetic measurements and from barrier theoretical calculations. ${ }^{17-19,21,24}$ Due to the difference of the imaginary frequencies of $\mathrm{TS}_{d}$, the $E_{2}$ parameter differs most among ab initio methods. All of them are, as expected, within or near the range of earlier theoretical studies. ${ }^{17-19,21,24}$ The calculated temperature dependence of rate constants has a non-Arrhenius effect at low temperatures and is quite robust in the present calculations.

The extrapolated low- and high-pressure rate constants $k^{0}$ and $k^{\infty}$ from the data of Fulle et al. ${ }^{5}$ and the calculations

TABLE VI. $\alpha$ values of several bath gases with various PESs. The units are $\mathrm{cm}^{-1}$.

\begin{tabular}{|c|c|c|c|c|c|c|c|c|c|c|}
\hline \multirow{2}{*}{$\begin{array}{l}\text { PES } \\
\text { ab initio }\end{array}$} & \multicolumn{4}{|c|}{$\mathrm{G} 2 \mathrm{M}$} & \multicolumn{4}{|c|}{ LTSH } & \multirow[b]{2}{*}{ Ref. 21} & \multirow[b]{2}{*}{ Ref. 22} \\
\hline & DFT-CC & DFT-MP & $\mathrm{CC}$ & MP2 & DFT-CC & DFT-MP & $\mathrm{CC}$ & MP2 & & \\
\hline $\mathrm{He}$ & 130 & 150 & 140 & 180 & 120 & 140 & 130 & 170 & 150 & $150^{\mathrm{a}}$ \\
\hline $\mathrm{Ar}^{\mathrm{b}}$ & 180 & 200 & 190 & 220 & 160 & 180 & 180 & 210 & 450 & 300 \\
\hline $\mathrm{N}_{2}$ & 190 & 240 & 200 & 300 & 170 & 230 & 190 & 280 & 250 & $300^{\mathrm{c}}$ \\
\hline $\mathrm{CF}_{4}$ & 270 & 380 & 300 & 460 & 250 & 340 & 270 & 440 & 450 & 680 \\
\hline $\mathrm{SF}_{6}$ & 350 & 500 & 400 & 700 & 320 & 450 & 360 & 650 & 1000 & 800 \\
\hline
\end{tabular}

${ }^{\mathrm{a}} 180 \mathrm{~cm}^{-1}$ for $\mathrm{OD}+\mathrm{CO}$ in $\mathrm{He}$.

${ }^{\mathrm{b}}$ Fitted to the data from the $\mathrm{OD}+\mathrm{CO}$ reaction.

${ }^{\mathrm{c}} 480 \mathrm{~cm}^{-1}$ for $\mathrm{OD}+\mathrm{CO}$ in $\mathrm{N}_{2}$. 


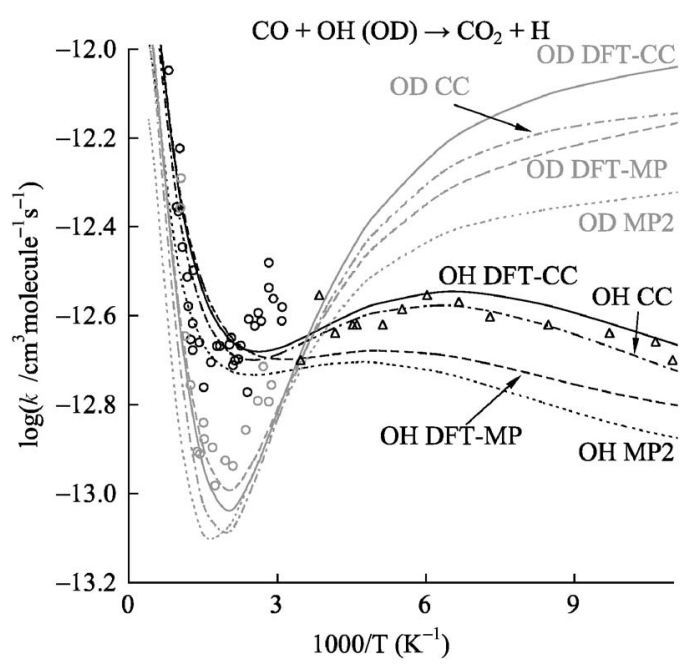

FIG. 8. Arrhenius plots for the reaction of $\mathrm{CO}+\mathrm{OH}$ (black lines) and $\mathrm{CO}$ + OD (gray lines) in Ar at 785 torr. All curves in the plot are obtained with G2M, and the LTSH potentials show similar curves. The black and gray open circles are the experimental data of $\mathrm{OH}$ and $\mathrm{OD}$ reacting with $\mathrm{CO}$, respectively (Ref. 4). The bath gas in the experiment consists of 760 torr of $\mathrm{Ar}$ and 15 torr of $\mathrm{H}_{2} \mathrm{O}$. The open triangles are Fulle's experiments at 760 torr of He. The solid, dot-dashed, dashed, and dotted lines are calculated with DFT-CC, CC, DFT-MP, and MP2, respectively.

with the step-down model are summarized in Table V. At the high-pressure limit, the rate constants are largely controlled by the properties of $\mathrm{TS}_{a}$. Since there are two kinds of $a b$ initio calculation levels, $\mathrm{CC}$ and $\mathrm{MP} 2$, for $\mathrm{TS}_{a}$, the highpressure rate constants $k^{\infty}$, $s$ in the calculations can be divided into two groups. The properties of $\mathrm{TS}_{a}$ described by MP2 and DFT-MP reproduce better the extrapolated experimental $k^{\infty}$ values by Fulle et al., but on the whole there is reasonable agreement.

The $\alpha$ values obtained using various PESs for various bath gases, listed in Table VI, form two groups. The force constants and structure of $\mathrm{TS}_{a}$ in DFT-CC and CC are the same and form a group, and those in DFT-MP and MP2 are the same and form a second group. Both sets of $\alpha$ are close to the $\alpha$ values independently fitted by Zhu et al..$^{21}$ and Senosiain et $_{\text {al. }}{ }^{22}$ (A caveat in comparing the step ladder $\alpha$ with the exponential down $\alpha$ was noted earlier.) The pressuredependent rates in various bath gases calculated by various $a b$ initio methods are similar to those in Fig. 4(a). Using the same force constants, the fitted $\alpha$ values from the G2M potential are slightly larger than those from LTSH, since the intermediate in the latter is stabler by about $1.5 \mathrm{kcal} \mathrm{mol}^{-1}$. The last observation is similar to the results of Senosiain et $a .^{22}$ Their fitted $\alpha$ value for He was reduced from 150 to $100 \mathrm{~cm}^{-1}$ when they lowered the energy of the HOCO* intermediates by $5.5 \mathrm{kcal} \mathrm{mol}^{-1}$. Thus, the pressure dependence of the rate constants is controlled by the properties of both $\mathrm{TS}_{a}$ and the stability of the HOCO* intermediate.

\section{2. $\mathrm{OH}$ and $\mathrm{OD}$}

The calculated $k_{\mathrm{OH}+\mathrm{CO}} / k_{\mathrm{OD}+\mathrm{CO}}$ ratio decreases to about 2 at 200 torr and about 1.2 at 700 torr using the various force constants for the various PESs. DFT-CC, DFT-MP, and CC overestimate the ratio at pressures lower than 100 torr.

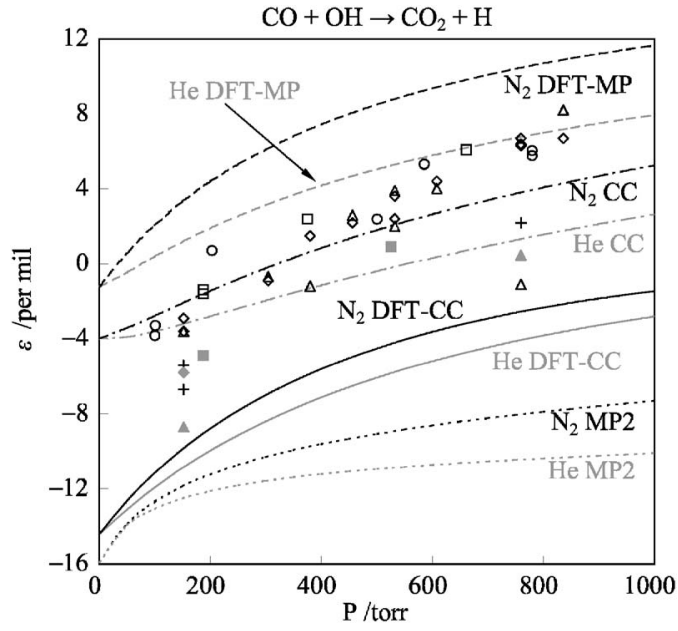

FIG. 9. The $\varepsilon{ }^{13} \mathrm{C}$ values for the system of $\mathrm{OH}+\mathrm{CO}$ as a function of total pressure at room temperature. Both G2M and LTSH potentials give similar results, only the calculations with G2M are shown in the plot. The gray and black lines are for $\mathrm{He}$ and $\mathrm{N}_{2}$ gases, respectively. The solid, dot-dashed, dashed, and dotted lines are calculated with DFT-CC, CC, DFT-MP, and MP2, respectively. The open circles are obtained for $\mathrm{N}_{2}$ by Smit et al. (Ref. 30). The gray solid and black open squares are obtained by Röckmann et al. (Ref. 31) for $\mathrm{He}$, and $\mathrm{N}_{2}$ (or $\mathrm{N}_{2}+\mathrm{O}_{2}$ ), respectively. Others are obtained by Stevens et al. (Ref. 29), where the gray and black indicate that the bath gases are $\mathrm{He}$ or $\mathrm{Ar}$, and $\mathrm{N}_{2}, \mathrm{O}_{2}$, or air, respectively.

The negative temperature effects in the $\mathrm{OD}+\mathrm{CO}$ reaction in the low-pressure limit are obtained for all PESs. The temperature for the minimum rate strongly depends on the imaginary frequency of $\mathrm{TS}_{d}$. The temperature with the minimum rate is around $400 \mathrm{~K}$ in $\mathrm{MP} 2,300 \mathrm{~K}$ in $\mathrm{CC}$, and $200 \mathrm{~K}$ in DFT-CC and DFT-MP, and is higher the higher the imaginary frequency. All Arrhenius plots of the $\mathrm{OH}$ and OD reacting with $\mathrm{CO}$ in Ar at 785 torr, shown in Fig. 8, are similar.

\section{Kinetic isotope effect for carbon}

Since the fractionation of ${ }^{13} \mathrm{C}$ is very small, the different sets of force constants yield slightly different results. However, all the calculated results show similar trends of the pressure dependence of the $\varepsilon{ }^{13} \mathrm{C}$ values between different bath gases, in agreement with the experimental data. The calculated pressure dependence of fractionation of ${ }^{13} \mathrm{C}$ is shown in Fig. 9. All calculations except MP2 give similar

TABLE VII. Parameters for fitting the rate constants at 100 and $300 \mathrm{~K}$ in the low-pressure limit. DFT-CC and CC methods are used with the G2M potential by nonstatistical model with $\xi$ at $4000 \mathrm{~cm}^{-1}$. The energy-transfer parameters $\alpha$ for various bath gases are also listed. The units are $\mathrm{cm}^{-1}$.

\begin{tabular}{lcc}
\hline \hline Ab initio & DFT-CC & CC \\
\hline$E_{1}$ & 0 & 10 \\
$E_{2}$ & -280 & 30
\end{tabular}

\begin{tabular}{lll} 
& & \\
\cline { 2 - 2 } & 120 & 140 \\
$\mathrm{Ar}^{\mathrm{a}}$ & 170 & 190 \\
$\mathrm{~N}_{2}$ & 190 & 210 \\
$\mathrm{CF}_{4}$ & 280 & 310 \\
$\mathrm{SF}_{6}$ & 360 & 410 \\
\hline \hline
\end{tabular}

${ }^{\mathrm{a}}$ Fitted to the data from the $\mathrm{OD}+\mathrm{CO}$ reaction. 


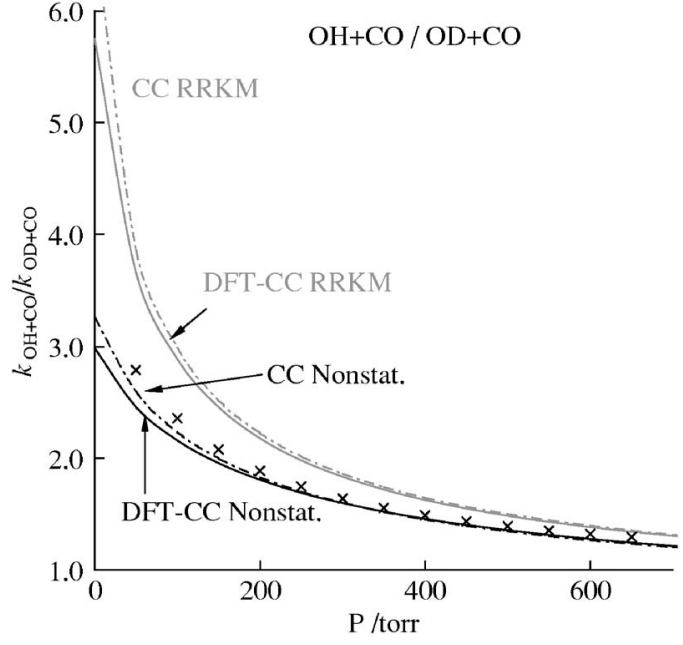

FIG. 10. Comparison of calculated and experimental results for the kinetic $\mathrm{OH} / \mathrm{OD}$ isotope effect as a function of pressure at room temperature. The experimental data ( $X$ 's) are taken from the fit to the data of Paraskevopoulos. The modified and unmodified RRKM theories are used in the calculation. The solid and dot-dashed lines are calculated with DFT-CC and CC, respectively.

pressure dependence. The reason for the inadequate pressure dependence calculated with MP2 is probably due to an overestimation of the imaginary frequency in $\mathrm{TS}_{d}$.

\section{Nonstatistical effect}

Since Eq. (C4) is used to approximate $\xi$ in the isotopesubstituted $\mathrm{HOCO}$, it decreases the ratio of the rate for $\mathrm{OH}$ $+\mathrm{CO}$ relative to $\mathrm{OD}+\mathrm{CO}$. In the nonstatistical effect only the two most accurate methods were used to test the accuracy of the nonstatistical modification, namely, the CC and DFT-CC methods together with the G2M potential. The value of $\xi$ in $\mathrm{HOCO}$ in both CC and DFT-CC is assumed to be $4000 \mathrm{~cm}^{-1}$. The parameters $E_{1}$ and $E_{2}$ adjusted to fit the rates of $\mathrm{OH}$

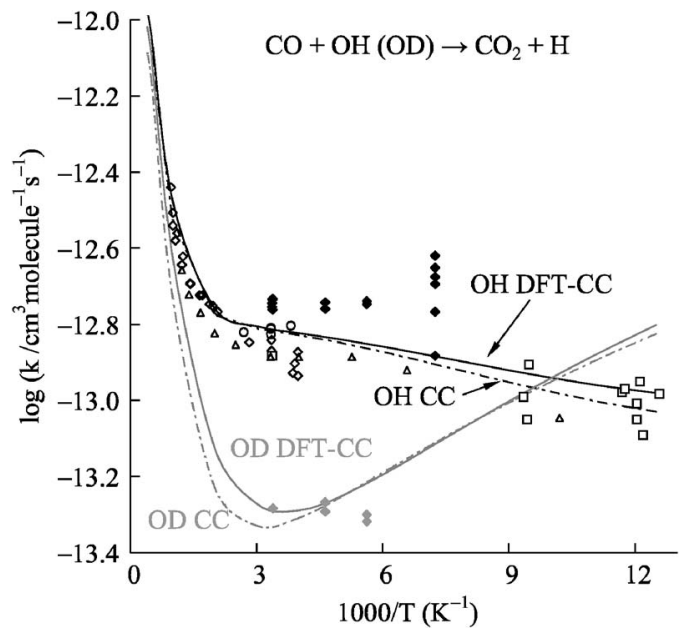

FIG. 11. Arrhenius plots for $\mathrm{CO}+\mathrm{OH}$ (black lines) and $\mathrm{CO}+\mathrm{OD}$ (gray lines) at the low-pressure limit. The solid and dot-dashed lines are calculated with DFT-CC and CC, respectively, at this limit. The open squares and solid diamonds are experimental results obtained for 2-10 torr by Frost et al. (Refs. 11,12). The open diamonds and circles are obtained at 100 and 50-92 torr, respectively, by Ravishankara and co-workers (Refs. 6 and 13). The open triangles are the extrapolated rate constants at zero pressure obtained by Fulle (Ref. 5).

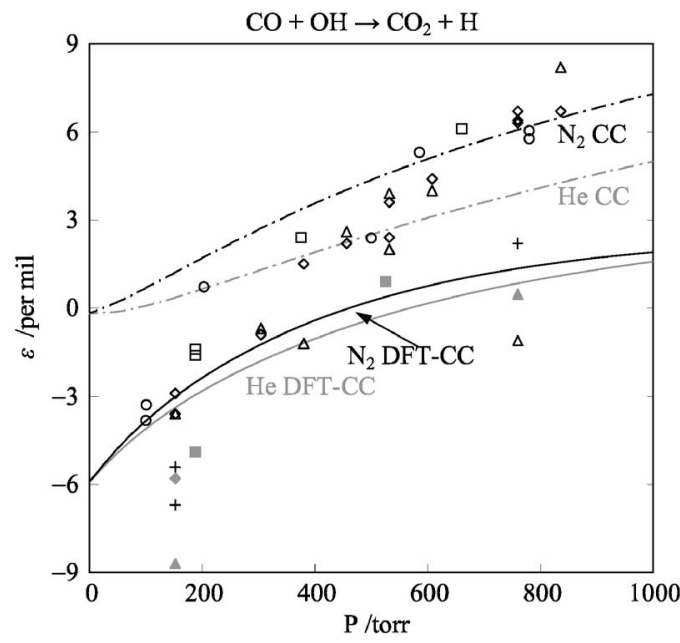

FIG. 12. The $\varepsilon{ }^{13} \mathrm{C}$ values for the system of $\mathrm{CO}+\mathrm{OH}$ by the nonstatistical model as a function of the total pressure. The solid and dot-dashed lines are calculated with DFT-CC and CC, respectively. The black and gray lines indicate the pressure dependence in $\mathrm{N}_{2}$ and He gases, respectively. The open circles are obtained for $\mathrm{N}_{2}$ by Smit et al. (Ref. 30). The gray solid and black open squares are obtained for $\mathrm{He}$ and $\mathrm{N}_{2}$ ( or $\mathrm{N}_{2}+\mathrm{O}_{2}$ ), respectively, by Röckmann et al. (Ref. 31). Others are obtained in by Smit et al. (Ref. 29). The gray and black indicate the bath gases as $\mathrm{He}$ or $\mathrm{Ar}$, and $\mathrm{N}_{2}, \mathrm{O}_{2}$, or air, respectively.

$+\mathrm{CO}$ at 100 and $300 \mathrm{~K}$ at low pressures and the energytransfer parameter $\alpha$ in various bath gases are listed in Table VII. The $\alpha$ values for the model are also similar to those for the conventional RRKM model, hence the pressure dependence of rate constants in both models are similar. However, for both $\mathrm{CC}$ and DFT-CC methods the nonstatistical model describes better the rate constant ratios between $\mathrm{OH}$ and $\mathrm{OD}$ reacting with $\mathrm{CO}$, as seen in Fig. 10. The negative temperature effect of the $\mathrm{OD}+\mathrm{CO}$ reaction is also observed in the model, shown in Fig. 11.

The kinetic isotope effects of carbon of DFT-CC are in better agreement with experiment at pressures under 400 torr when this nonstatistical correction is used, as seen in Fig. 12. Although the values obtained with $\mathrm{CC}$ agree better at pressures higher than 500 torr, both DFT-CC and CC give a similar trend for the pressure dependence of $\varepsilon{ }^{13} \mathrm{C}$.

\section{APPENDIX B: THE TUNNELING PROBABILITY FOR AN ECKART BARRIER}

For the Eckart potential, frequently used to estimate the tunneling probability of the reaction, ${ }^{68}$ the transmission probability as a function of energy $E$ is

$$
\kappa(E)=1-\frac{\cosh (a-b)+\cosh (c)}{\cosh (a+b)+\cosh (c)},
$$

where

$$
\begin{gathered}
a=\frac{4 \pi E^{1 / 2}}{h \nu^{*}\left(V_{1}^{-1 / 2}+V_{2}^{-1 / 2}\right)}, \quad b=\frac{4 \pi\left(E-V_{1}+V_{2}\right)^{1 / 2}}{h \nu^{*}\left(V_{1}^{-1 / 2}+V_{2}^{-1 / 2}\right)}, \\
c=4 \pi\left(\frac{V_{1} V_{2}}{\left(h \nu^{*}\right)^{2}}-\frac{1}{16}\right)^{1 / 2},
\end{gathered}
$$

$V_{1}$ is the barrier height relative to the beginning of the barrier and $V_{2}$ is the barrier height relative to the products. The 


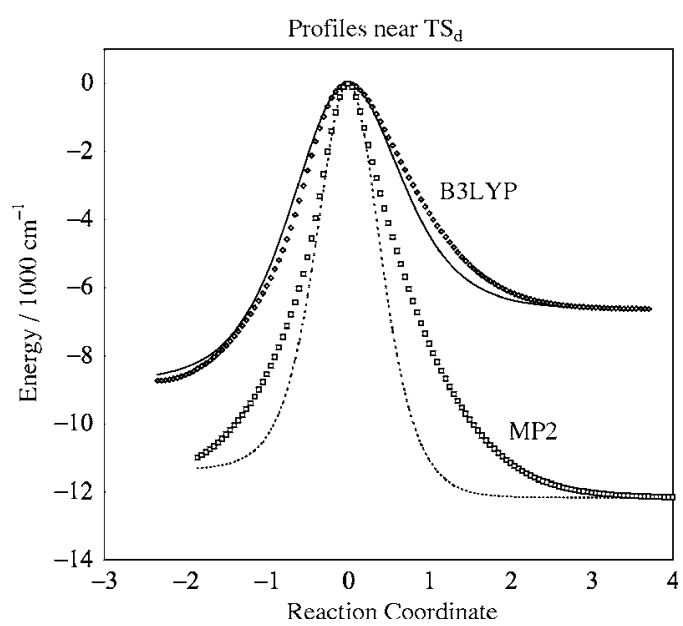

FIG. 13. Comparison of different barrier profiles with Eckart potential functions and with IRC calculations. The open diamonds and open squares denote the IRC calculations at $\mathrm{TS}_{d}$ calculated with B3LYP and MP2, respectively. The solid and dotted lines were obtained using the Eckart potential for the exit channel using B3LYP and MP2, respectively.

potential is written for an exoergic reaction, i.e., $V_{1} \leqslant V_{2}$, and $\nu^{*}$ is the absolute value of the imaginary frequency.

The GAUSSIAN 98 program supports the intrinsic reaction coordinate (IRC) calculation for the MP2 and DFT methods, but not for the $\mathrm{CC}$ method. Since the value of the imaginary frequency of $\mathrm{TS}_{d}$ by $\mathrm{CC}$ is intermediate between those obtained using the other methods, the difference between the barrier profiles estimated by the Eckart potential functions and calculated by the IRC method with DFT or MP2, shown in Fig. 13, would be expected to reflect the nature of any error in using the Eckart potential to approximate calculations by $\mathrm{CC}$. The Eckart potential is sharper than that obtained by the IRC calculation, especially when the imaginary frequency is large. (The imaginary frequency is $1526 i \mathrm{~cm}^{-1}$ in DFT and $3372 i \mathrm{~cm}^{-1}$ in MP2.) However, most of the tunneling region occurs between the top of the barrier at $\mathrm{TS}_{d}$ and about $1500 \mathrm{~cm}^{-1}$ below it. In comparing the tunneling probabilities through Eckart and parabolic barriers, the shape of the bottom of the barrier has a negligible effect on the reaction rate constants. We infer that an Eckart potential is a reasonable barrier to approximate the tunneling effect in the current study.

\section{APPENDIX C: EQUATION FOR THE NONSTATISTICAL MODEL}

In a trial intramolecular energy-transfer model, we assume that only a limited amount of energy, $\xi$, can be transferred into or out of $\mathrm{OH}$ stretching just before the HOCO* passes through $\mathrm{TS}_{d}$. The dissociation rate of $\mathrm{HOCO}^{*}$ at a total energy $E$, rotational quantum state $J$, and quantum number $n$ of $\mathrm{OH}$ stretching in $\mathrm{HOCO}^{*}$ is then

$$
k_{n}(E J)=\frac{N_{n}(E J)}{h \rho_{n}(E J)},
$$

where

$$
N_{n}(E J)=\int_{\operatorname{Max}\left[E_{0}, E_{0}+n h \nu-\xi\right]}^{\operatorname{Min}\left[E, E_{0}+n h \nu+\xi\right]} \kappa_{d}\left(E^{\prime}\right) \rho_{d}\left(\left(E-E^{\prime}\right) J\right) \mathrm{d} E^{\prime} .
$$

The definitions of $\kappa_{d}\left(E^{\prime}\right)$ and $\rho_{d}\left(\left(E-E^{\prime}\right) J\right)$ are the same as in Eq. (7). $\nu$ is the $\mathrm{OH}$-stretching frequency of cis-HOCO, and the lower and upper bounds of the integral correspond respectively to the maxima value between $E_{0}$ and $E_{0}+n h \nu-\xi$ and the minima value between $E_{0}$ and $E_{0}+n h \nu+\xi$. The dissociation rate of $\mathrm{HOCO}^{*}$ at total energy $E$ and rotational state $J$ can be expressed from Eq. (C1) as

$$
k(E J)=\frac{1}{n_{\max }} \sum_{n=0}^{n_{\max }} \frac{\rho_{n}(E J)}{\rho(E J)} k_{n}(E J),
$$

where $n_{\max }$ is the maximum allowed quantum number of the $\mathrm{OH}$ stretching in the energetic intermediate at $(E, J), \rho_{n}(E J)$ is the density of states of the intermediate at $\mathrm{OH}$ vibrational state $n$, and $\rho(E J)$ is the total density of states at total energy $E$ and rotational state $J$.

The energy-transfer parameter $\xi$ depends on the difference in resonances of the $\mathrm{OH}$-stretching vibration with other modes and on the anharmonic coupling of the PES. It can also influence the isotope effects. As a first approximation, and similarly as in Eq. (10) in the deuterium case, $\xi_{\text {iso }}$ is written as

$$
\xi_{\text {iso }}=\frac{\nu}{\nu_{\text {iso }}} \xi,
$$

where $\nu$ is the $\mathrm{OH}$-stretching frequency in the intermediate and the subscript "iso" and no subscript indicates the isotope-substituted $\mathrm{HOCO}$ and normal isotopologue of $\mathrm{HOCO}$, respectively. Although a very crude approximation, the equation includes the fact that the internal energy transfer would be more rapid when the stretching frequency is closer to that of the other modes. For example, the $\xi$ value in DOCO calculated from the approximation is about $40 \%$ larger than that in HOCO.

${ }^{1}$ R. P. Wayne, Chemistry of Atmospheres, 3rd ed. (Oxford University Press, New York, 2000).

${ }^{2}$ Combustion Chemistry, edited by W. C. Gardiner, Jr. (Springer, New York, 1984).

${ }^{3}$ A. Miyoshi, H. Matsui, and N. Washida, J. Chem. Phys. 100, 3532 (1994).

${ }^{4}$ C. D. Jonah, W. A. Mulac, and P. Zeglinski, J. Phys. Chem. 88, 4100 (1984).

${ }^{5}$ D. Fulle, H. F. Hamann, H. Hippler, and J. Troe, J. Chem. Phys. 105, 983 (1996)

${ }^{6}$ A. R. Ravishankara and R. L. Thompson, Chem. Phys. Lett. 99, 377 (1983).

${ }^{7}$ V. Lissianski, H. Yang, Z. Qin, M. R. Mueller, and K. S. Shin, Chem. Phys. Lett. 240, 57 (1995).

${ }^{8}$ M. S. Wooldridge, R. K. Hanson, and C. T. Bowman, Int. J. Chem. Kinet. 28, 361 (1996).

${ }^{9}$ M. S. Wooldridge, R. K. Hanson, and C. T. Bowman, 25th International Symposium on Combustion, University of California at Irvine, Irvine, CA, 13 July-5 August 1994 (The Combustion Institute, Pittsburgh, PA, 1994), pp. 741-748.

${ }^{10}$ T. A. Brabbs, F. E. Belles, and R. S. Brokaw, 13th International Symposium on Combustion, University of Utah, 23-29 August 1970 (The Combustion Institute, Pittsburgh, PA, 1971), pp. 129-136.

${ }^{11}$ M. J. Frost, P. Sharkey, and I. W. M. Smith, J. Phys. Chem. 97, 12254 (1993).

${ }^{12}$ M. J. Frost, P. Sharkey, and I. W. M. Smith, Faraday Discuss. Chem. Soc. 91, 305 (1991). 
${ }^{13}$ A. J. Hynes, P. H. Wine, and A. R. Ravishankara, J. Geophys. Res. 91 11815 (1986).

${ }^{14}$ A. Hofzumahaus and F. Stuhl, Ber. Bunsenges. Phys. Chem. 88, 557 (1984).

${ }^{15}$ R. Forster, M. Frost, D. Fulle, H. F. Hamann, H. Hippler, A. Schlepegrell, and J. Troe, J. Chem. Phys. 103, 2949 (1995).

${ }^{16}$ N. F. Scherer, C. Sipes, R. B. Bernstein, and A. H. Zewail, J. Chem. Phys. 92, 5239 (1990).

${ }^{17}$ D. M. Golden, G. P. Smith, A. B. McEwen et al., J. Phys. Chem. A $\mathbf{1 0 2}$ 8598 (1998)

${ }^{18}$ H. G. Yu, J. T. Muckerman, and T. J. Sears, Chem. Phys. Lett. 349, 547 (2001).

${ }^{19}$ T. V. Duncan and C. E. Miller, J. Chem. Phys. 113, 5138 (2000).

${ }^{20}$ R. Valero and G. J. Kroes, J. Chem. Phys. 117, 8736 (2002).

${ }^{21}$ R. S. Zhu, E. G. W. Diau, M. C. Lin, and A. M. Mebel, J. Phys. Chem. A 105, 11249 (2001).

${ }^{22}$ J. P. Senosiain, C. B. Musgrave, and D. M. Golden, Int. J. Chem. Kinet. 35, 464 (2003).

${ }^{23}$ R. Valero, D. A. McCormack, and G. J. Kroes, J. Chem. Phys. 120, 4263 (2004).

${ }^{24}$ M. J. Lakin, D. Troya, G. C. Schatz, and L. B. Harding, J. Chem. Phys. 119, 5848 (2003).

${ }^{25}$ D. M. Medvedev, S. K. Gray, E. M. Goldfield, M. J. Lakin, D. Troya, and G. C. Schatz, J. Chem. Phys. 120, 1231 (2004).

${ }^{26}$ K. L. Feilberg, G. D. Billing, and M. S. Johnson, J. Phys. Chem. A 105, 11171 (2001).

${ }^{27}$ J. P. Senosiain, S. J. Klippenstein, and J. A. Miller, Proc. Combust. Inst. 30, 945 (2005).

${ }^{28}$ J. Troe, Proc. Combust. Inst. 27, 167 (1998).

${ }^{29}$ C. M. Stevens, L. Kaplan, R. Gorse, S. Durkee, M. Compton, S. Cohen, and K. Bielling, Int. J. Chem. Kinet. 12, 935 (1980).

${ }^{30}$ H. G. J. Smit, A. Volz, D. H. Ehhalt, and H. Knappe, in Stable Isotopes, edited by H. Schmidt, H. Förstel, and K. Heinzinger (Elsevier, New York, 1982), pp. 147-152.

${ }^{31}$ T. Röckmann, C. A. M. Brenninkmeijer, G. Saueressig, P. Bergamaschi, J. N. Crowley, H. Fischer, and P. J. Crutzen, Science 281, 544 (1998).

${ }^{32}$ K. L. Feilberg, S. R. Sellevag, C. J. Nielsen, D. W. T. Griffith, and M. S. Johnson, Phys. Chem. Chem. Phys. 4, 4687 (2002).

${ }^{33}$ K. L. Feilberg, M. S. Johnson, and C. J. Nielsen, Phys. Chem. Chem. Phys. 11, 2318 (2005).

${ }^{34}$ B. Ruscic, M. Schwarz, and J. Berkowitz, J. Chem. Phys. 91, 6780 (1989).

${ }^{35}$ B. Ruscic and M. Litorja, Chem. Phys. Lett. 316, 45 (2000).

${ }^{36}$ M. E. Jacox, J. Chem. Phys. 88, 4598 (1988).

${ }^{37}$ J. T. Petty, J. A. Harrison, and C. B. Moore, J. Phys. Chem. 97, 11194 (1993).

${ }^{38}$ J. Nolte, J. Grussdorf, E. Temps, and H. G. Wagner, Z. Naturforsch., A: Phys. Sci. 48, 1234 (1993).

${ }^{39}$ G. Poggi and J. S. Francisco, J. Chem. Phys. 120, 5073 (2004).

${ }^{40}$ G. Paraskevopoulos and R. S. Irwin, J. Chem. Phys. 80, 259 (1984).

${ }^{41}$ G. Paraskevopoulos and R. S. Irwin, Chem. Phys. Lett. 93, 138 (1982).

${ }^{42}$ J. Bigeleisen and M. G. Mayer, J. Chem. Phys. 15, 261 (1947).

${ }^{43}$ D. H. Volman, J. Photochem. Photobiol., A 100, 1 (1996).

${ }^{44}$ The vibrational frequencies and rotational constants of all stationary structures are calculated by the $\operatorname{CCSD}(\mathrm{T})$ method with the $6-31 \mathrm{G}(d, p)$ basis set.
${ }^{45}$ With the same values of $\alpha$ for various bath gases, the difference of calculated rates by using the rotational constants and vibrational frequencies between CC and Yu et al. (Ref. 18) is less than 1\% as pressure is under 1000 torr. The values of carbon-isotope fractionation by $\mathrm{CC}$ is higher than the other by around 1 per mil at low pressure and around 2.5 per mil at $1 \mathrm{~atm}$. Thus, the structures and vibrational frequencies by $\mathrm{CC}$ is good enough for this study.

${ }^{46}$ Recent high-level $a b$ initio calculations are considered in the energies of stationary points in the LTSH potential. Since the imaginary frequency of $\mathrm{TS}_{d}$ in the LTSH potential is too low, the vibrational frequencies and rotational constants of all stationary structures are calculated by ab initio methods. Only the energies without ZPE corrections of the stationary structures are obtained from the LTSH potential.

${ }^{47}$ M. J. Frisch, G. W. Trucks, H. B. Schlegel et al., GAUSSIAN 98, revision A.11.3, Gaussian, Inc., Pittsburgh, PA, 2002.

${ }^{48}$ The tunneling corrections for microcanonical systems were described by Marcus (Ref. 50). Instead of the usual sum over states $N(E J), \Sigma 1$, one sums over the TS-dependent tunneling over probabilities $\Sigma \kappa(\epsilon J)$ for $\epsilon$ $<E$. A similar prescription is given by Miller (Ref. 51). The details about evaluating the tunneling probability are described in Sec. II C.

${ }^{49}$ Including the loose transition structure forming $\mathrm{OH} \cdots \mathrm{CO}$, the rates are decreased by about $5 \%$ at room temperature. It has negligible effects on the rate constant ratios for $\mathrm{OH}$ and $\mathrm{OD}$ reacting with $\mathrm{CO}$ at pressures below 1000 torr. The difference in fractionation of the carbon isotope calculated with and without the additional loose transition structure in the calculation for the present pressures $0-1000$ torr and room-temperature regions is about 0.5 per mil.

${ }^{50}$ R. A. Marcus, J. Chem. Phys. 45, 2138 (1966).

${ }^{51}$ W. H. Miller, J. Am. Chem. Soc. 101, 6810 (1979).

${ }^{52}$ J. Troe, J. Chem. Phys. 79, 6017 (1983).

${ }^{53}$ The rotational barrier was obtained from the high-level ab initio calculations by Yu et al. (Ref. 18).

${ }^{54}$ The sharp barrier at $\mathrm{TS}_{d}$ is not included in any analytical potential functions by Schatz et al. (Refs. 25 and 46).

${ }^{55}$ R. A. Marcus, J. Chem. Phys. 45, 4500 (1966).

${ }^{56}$ C. Eckart, Phys. Rev. 35, 1303 (1930).

${ }^{57}$ Y. Q. Gao and R. A. Marcus, J. Chem. Phys. 114, 9807 (2001).

${ }^{58}$ Y. Q. Gao and R. A. Marcus, J. Chem. Phys. 116, 137 (2002).

${ }^{59}$ As the exponential model is used to test the convergence, the results of grain size in 5 and $10 \mathrm{~cm}^{-1}$ are the same.

${ }^{60}$ R. A. Marcus, J. Chem. Phys. 62, 1372 (1975).

${ }^{61}$ G. Worry and R. A. Marcus, J. Chem. Phys. 67, 1636 (1977).

${ }^{62}$ S. J. Klippenstein and R. A. Marcus, J. Chem. Phys. 93, 2418 (1990).

${ }^{63}$ M. Brouard, D. W. Hughes, K. S. Kalogerakis, and J. P. Simons, J. Phys. Chem. A 102, 9559 (1998).

${ }^{64}$ M. Brouard, D. W. Hughes, K. S. Kalogerakis, and J. P. Simons, J. Chem. Phys. 112, 4557 (2000).

${ }^{65}$ M. Brouard, I. Burak, D. W. Hughes, K. S. Kalogerakis, J. P. Simons, and V. Stavros, J. Chem. Phys. 113, 3173 (2000).

${ }^{66}$ The experimental rate constants at low pressure near $300 \mathrm{~K}$ are in the range of $(1.3-1.8) \times 10^{-13} \mathrm{~cm}^{3}$ molecule ${ }^{-1} \mathrm{~s}^{-1}$. The rate constant is chosen by a best fit to the pressure dependence at $300 \mathrm{~K}$.

${ }^{67}$ The HO-CO distance of $\mathrm{TS}_{a}$ optimized by B3LYP is too long, which is around $2.99 \AA$ in B3LYP, so doubtful frequencies would be expected. A similar result happened when Lin used B3LYP/6-311G $(d, p)$ to calculate $\mathrm{TS}_{a}$. (Ref. 21).

${ }^{68}$ H. S. Johnston and J. Heicklen, J. Phys. Chem. 66, 532 (1962). 